\title{
Effects of Clostridium butyricum on growth performance, metabonomics and intestinal microbial differences of weaned piglets
}

Jing Liang ${ }^{1}$, Shasha Kou', Cheng Chen', Sayed Haidar Abbas Raza ${ }^{2}$, Sihu Wang ${ }^{2}, X_{i}$ Ma $^{1,3}$, Wen-Ju Zhang ${ }^{1 *}$ and Cunxi $\mathrm{Nie}^{1^{*}}$

\begin{abstract}
Background: Weaning stress of piglets causes a huge economic loss to the pig industry. Balance and stability of the intestinal microenvironment is an effective way to reduce the occurance of stress during the weaning process. Clostridium butyricum, as a new microecological preparation, is resistant to high temperature, acid, bile salts and some antibiotics. The aim of present study is to investigate the effects of $C$. butyricum on the intestinal microbiota and their metabolites in weaned piglets.

Results: There was no statistical significance in the growth performance and the incidence of diarrhoea among the weaned piglets treated with $C$. butyricum during 0-21 days experimental period. Analysis of 165 rRNA gene sequencing results showed that the operational taxonomic units (OTUs), abundance-based coverage estimator (ACE) and Chao index of the CB group were found to be significantly increased compared with the NC group $(P<0.05)$. Bacteroidetes, Firmicutes and Tenericutes were the predominant bacterial phyla in the weaned piglets. A marked increase in the relative abundance of Megasphaera, Ruminococcaceae_NK4A214_group and Prevotellaceae_UCG-003, along with a decreased relative abundance of Ruminococcaceae_UCG-005 was observed in the CB group, when compared with the NC group $(P<0.05)$. With the addition of $C$. butyricum, a total of twenty-two significantly altered metabolites were obtained in the feces of piglets. The integrated pathway analysis by MetaboAnalyst indicated that arginine and proline metabolism; valine, leucine and isoleucine biosynthesis; and phenylalanine metabolism were the main three altered pathways, based on the topology. Furthermore, Spearman's analysis revealed some altered gut microbiota genus such as Oscillospira, Ruminococcaceae_NK4A214_group, Megasphaera, Ruminococcaceae_UCG-005, Prevotella_2,

Ruminococcaceae_UCG-002, Rikenellaceae_RC9_gut_group and Prevotellaceae_UCG-003 were associated with the alterations in the fecal metabolites $(P<0.05)$, indicating that $C$. butyricum presented a potential protective impact through gut microbiota. The intestinal metabolites changed by C. butyricum mainly involved the variation of citrulline, dicarboxylic acids, branched-chain amino acid and tryptophan metabolic pathways.

Conclusions: Overall, this study strengthens the idea that the dietary C. butyricum treatment can significantly alter the intestinal microbiota and metabolite profiles of the weaned piglets, and C. butyricum can offer potential benefits for the gut health.
\end{abstract}

Keywords: Clostridium butyricum, Growth performance, Intestinal microbiota, Metabolomics, Weaned piglet

\footnotetext{
*Correspondence: zhangwj1022@sina.com; niecunxi@shzu.edu.cn

${ }^{1}$ College of Animal Science and Technology, Shihezi University, Shihezi,

Xinjiang 832003, People's Republic of China

Full list of author information is available at the end of the article
}

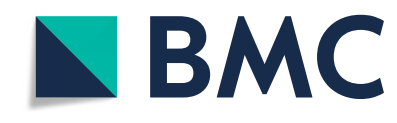

(ㄷ) The Author(s). 2021 Open Access This article is licensed under a Creative Commons Attribution 4.0 International License, which permits use, sharing, adaptation, distribution and reproduction in any medium or format, as long as you give appropriate credit to the original author(s) and the source, provide a link to the Creative Commons licence, and indicate if changes were made. The images or other third party material in this article are included in the article's Creative Commons licence, unless indicated otherwise in a credit line to the material. If material is not included in the article's Creative Commons licence and your intended use is not permitted by statutory regulation or exceeds the permitted use, you will need to obtain permission directly from the copyright holder. To view a copy of this licence, visit http://creativecommons.org/licenses/by/4.0/. The Creative Commons Public Domain Dedication waiver (http://creativecommons.org/publicdomain/zero/1.0/) applies to the data made available in this article, unless otherwise stated in a credit line to the data. 


\section{Background}

Weaning stressors are generally associated with the changes in environment, diet, management, and separation from the mother that exhibit a negative impact on the growth performance and intestinal health of the young animals, leading to diarrhoea, slow growth, and decreased ability to resist disease [1]. Alleviating stress damage caused by weaning in piglets is an urgent problem to be solved. In the last few years, antibiotics have acted a pivotal part in controlling the diseases in animals, and improving animal growth and reproductive performance. However, antibiotics can improve the tolerance of pathogenic bacteria, kill beneficial bacteria, and may cause a damage to the environment. With this background, the Ministry of Agriculture and Rural Affairs of the People's Republic of China in 2020 has restricted the use of antibiotics as growth promoters in animal feed. Thus, there is an urgency to find an efficient alternative to reduce the economic losses caused by this prohibition. Several studies have demonstrated that the microbial ecological agents, organic acids, essential oils and probiotics can act as the potential alternatives for the use of antibiotics [2-5].

The probiotic $C$. butyricum is well known grampositive and obligate anaerobic bacillus [6] that can colonise the intestinal tract of animals [7]. As an important constituent of probiotics, C. butyricum has been used to prevent or treat the intestinal disorders of animals [810]. Apart from the beneficial effects on intestinal tract, C. butyricum addition was recently reported to promote the growth in animals [11-15], improve immune response $[16,17]$, and regulate the structure and composition of gut microbiota in livestock [18-20]. Gut microbiota affects the digestion and absorption of nutrients [21, 22], and the microbial metabolites associated with them are known to cause majority of the biological effects [23].

Metabolomics has an enormous potential for studying the functions in complex systems and expanding knowledge about gut microbial metabolism [24]. Metabolomics has been used to study the metabolism of pigs at present $[25,26]$. Although there are several studies on $C$. butyricum in livestock, the microbiome-metabolomics analysis has been not extensively studied, especially in the piglets. Recent studies have described the microbial production and bioavailabilities of xenometabolites and their derivatives, which makes it important to understand the influence of the microbiota on the host physiology [27]. Therefore, the present study was conducted in order to assess the effects of C. butyricum on the growth performance, metabonomics and intestinal microbial differences in weaned piglets by sequencing of the 16S rRNA gene and a liquid chromatography-mass spectrometry (LC-MS) platform based metabolomics.
Furthermore, we attempted to explore the possible relationship between the bodyweight, incidence of diarrhea, intestinal microbiota and metabolomics.

\section{Methods}

\section{Animals, diet, and sampling}

Ninety crossbred [(Yorkshire $\times$ Landrace $) \times$ Duroc] piglets (male: female was 45: 45) with $(6.22 \pm 0.24) \mathrm{kg}$ of body weight weaned at $(28 \pm 2)$ days of age were randomly allocated into 3 groups with 6 replicates per group and 5 piglets in each replicate. They were NC group (control diet, negative control), PC group [control diet $+0.1 \mathrm{~g}$ antibiotic (colistin sulphate) $/ \mathrm{kg}$ of control diet] and $\mathrm{CB}$ group (control diet $+5 \times 10^{8} \mathrm{CFU} C$. butyricum $/ \mathrm{kg}$ of control diet). The diets were fed in amounts that met or exceeded National Research Council (NRC) nutrient recommendations [28]. The C. butyricum culture was obtained from the Zhejiang Huijia Bio-technology Co., Ltd. (Zhejiang, China). It was isolated from the contents of pig intestines. The strain number was HJCB998 and preserved by China General Microbiological Culture Collection Center (CGMCC). Colistin sulphate was purchased by the veterinary drug factory of Shihezi city. The composition and nutrient content of the control diets are shown in Table 1. The feeding management of piglets, the measurement and calculation of average daily gain (ADG), average daily feed intake (ADFI), feed to gain ratio $(F / G)$ and diarrhoea incidence were followed by our previous study [29]. Faecal samples of the piglets were

Table 1 Composition and nutrient levels of control diet (airdried basis, \%)

\begin{tabular}{llll}
\hline Ingredients & Content & Nutrient levels $^{\mathbf{b}}$ & Content \\
\hline Corn & 58.60 & Digestible energy (MJ/kg) & 13.68 \\
Soybean meal & 17.50 & & \\
Expanded soybean & 7.50 & Crude protein & 20.40 \\
Milk powder & 4.00 & Lys & 1.30 \\
Fish meal & 4.00 & Met+Cys & 0.78 \\
Whey power & 4.30 & Thr & 0.87 \\
NaCl & 0.30 & Na & 0.27 \\
Limestone & 1.22 & Ca & 0.95 \\
CaHPO & 1.16 & Available P & 0.39 \\
DL-met & 0.07 & & \\
Lys.HCL & 0.35 & & \\
Premix & 1.00 & & \\
Total & 100.00 & & \\
\hline
\end{tabular}

${ }^{a}$ The premix provided the per kg of diet as follows: VA $8000 \mathrm{IU}, \mathrm{VB}_{1} 4 \mathrm{mg}, \mathrm{VB}_{2}$ $3.6 \mathrm{mg}, \mathrm{VB}_{5} 40 \mathrm{mg}, \mathrm{VB}_{6} 4 \mathrm{mg}, \mathrm{VB}_{12} 0.02 \mathrm{mg}, \mathrm{VD}_{3} 3000 \mathrm{IU}, \mathrm{VE} 20 \mathrm{IU}, \mathrm{VK}_{3} 2 \mathrm{mg}$, biotin 0.15 , folic acid $1 \mathrm{mg}$, D-pantothenic acid $11 \mathrm{mg}$, nicotinic acid $10 \mathrm{mg}$, antioxidant $100 \mathrm{mg}, \mathrm{Cu}$ (as copper sulfate) $10 \mathrm{mg}$, Fe (as ferrous sulfate) $80 \mathrm{mg}$, $\mathrm{Mn}$ (as manganese sulfate) $30 \mathrm{mg}, \mathrm{Zn}$ (as zinc sulfate) $75 \mathrm{mg}, \mathrm{I}$ (as potassium iodide) $0.4 \mathrm{mg}$, Se (as sodium selenite) $0.3 \mathrm{mg}$. ${ }^{\mathrm{b}}$ Digestible energy and Available $P$ were calculated values, while the others were measured values 
collected by rectal stimulation on day 21 . Three piglets were randomly selected from each group, the faecal samples were stored in cryosurgery tubes, immediately deepfrozen in liquid nitrogen and stored at $-80^{\circ} \mathrm{C}$ until further analysis.

\section{DNA extraction, illumina miseqsequencing, and data processing}

Microbial DNA was extracted from the faecal samples utilizing the TIANamp Stool QIAamp PowerFecal DNA Kit (QIAGEN, Hilden, Germany) according to the manufacturer's protocols [26]. DNA concentration and purification were settled determined by NanoDrop 2000 UV-vis spectrophotometer (Thermo Scientific, Wilmington, USA), and the DNA quality was checked by $1 \%$ agarose gel electrophoresis. The hypervariable regions of the bacteria $16 \mathrm{~S}$ rRNA gene were amplified with primers 515F (5'-GTGCCAGCMGCCGCGGTAA-3') and 907R (5' -CCGTCAATTCCTTTGAGTTT-3') [30] by utilizing a thermocycler PCR system (GeneAmp 9700, ABI, USA). PCR cycles were conducted using an accompanying programme: denaturation of $3 \mathrm{~min}$ at $95^{\circ} \mathrm{C}$, subjected to 27 cycles of $30 \mathrm{~s}$ at $95^{\circ} \mathrm{C}, 30 \mathrm{~s}$ for annealing at $55^{\circ} \mathrm{C}$, elongation of $45 \mathrm{~s}$ at $72^{\circ} \mathrm{C}$, followed by a final extension step for $10 \mathrm{~min}$ at $72^{\circ} \mathrm{C}$. PCR were performed in triplicate $20 \mu \mathrm{L}$ mixtures including $4 \mu \mathrm{L}$ of $5 \times$ FastPfu Buffer, $2 \mu \mathrm{L}$ of $2.5 \mathrm{mM}$ dNTPs, $0.8 \mu \mathrm{L}$ of each primer $(5 \mu \mathrm{M}), 0.4 \mu \mathrm{L}$ of FastPfu Polymerase and $10 \mathrm{ng}$ of template DNA. The resultant PCR products were collected from a $2 \%$ agarose gel and then further purified with an AxyPrep DNA Gel Extraction Kit (Axygen Biosciences, Union City, CA, USA) and quantified by using QuantiFluor $^{\mathrm{TM}}$-ST (Promega, USA) according to the manufacturer's suggested protocol. Purified amplicons were pooled in equimolar solutions and comprised $2 \times 300$-bp paired-end reads on an Illumina MiSeq platform (Illumina, San Diego, USA) [9] according to the standard protocols by Majorbio Bio-Pharm Technology Co. Ltd. (Shanghai, China). The raw sequencing data were submitted to the NCBI Sequence Read Archive (SRA, NCBI, http://www.ncbi.nlm.nih.gov/sra) as available under accession number PRJNA679135.

Raw FASTQ files were quality-filtered by Trimmomatic and merged by Fast Length Adjustment of Short Reads (FLASH) based on the following criteria: The reads were truncated at any site receiving an average quality score $<20$ over a $50 \mathrm{bp}$ sliding window. Sequences whose overlap was longer than $10 \mathrm{bp}$ were merged according to their overlap with mismatch, not more than $2 \mathrm{bp}$. Sequences of each sample were separated, primers, read and the ambiguous bases were removed [31, 32]. OTUs were obtained based on a $97 \%$ similarity cut-off by UPARSE (version 7.1 http://drive5.com/uparse/) [9]. The taxonomy of each sequence of $16 \mathrm{~S}$ rRNA gene was analysed by the Ribosomal Database Project (RDP) Classifier algorithm (http://rdp.cme.msu.edu/) against the full SILVA 16S rRNA gene reference database (https://www.arb-silva. de/) with a $70 \%$ confidence threshold [9].

\section{LC-MS analysis}

The chromatographic separation was carried out on an ACQUITY UPLC ${ }^{\circledast} \mathrm{HSS}$ T3 column maintained at $40^{\circ} \mathrm{C}$ using an ACQUITY UPLC system. The column dimensions and particle size were $2.1 \times 150 \mathrm{~mm}, 1.8 \mu \mathrm{m}$. The autosampler temperature was set at $4{ }^{\circ} \mathrm{C}$. Gradient elution of the analytes was carried out with a mobile phase of $0.1 \%(\mathrm{v} / \mathrm{v})$ formic acid in water $(\mathrm{A})$ and $0.1 \%(\mathrm{v} / \mathrm{v})$ formic acid in acetonitrile (B). The flow rate for the mobile phase was $0.25 \mathrm{~mL} / \mathrm{min}$. The injection volume was $6 \mu \mathrm{L}$ for each sample after equilibration. A linear gradient was run as follows: $0-1 \mathrm{~min}$, maintain at $2 \%$ solvent $\mathrm{B}$; $1-9.5$ min, 2-50\% solvent B; 9.5-14 min, 50-98\% solvent B; 14-15 min, 98\% solvent B; 15-15.5 min, 98-2\% solvent $\mathrm{B}$; and $15.5-17 \mathrm{~min}, 2 \%$ solvent $\mathrm{B}$ [33].

The ESI-MSn experiments were performed on a Thermo LTQ-Orbitrap XL mass spectrometer (Bremen, Germany) with the spray voltage in positive ion mode was $4.8 \mathrm{kV}$ and $4.5 \mathrm{kV}$ in negative ion mode. Auxiliary gas and sheath gas were maintained at 15 and 45 arbitrary units and capillary temperature was set at $325^{\circ} \mathrm{C}$. The voltages of the tube and capillary were $50 \mathrm{~V}$ and 35 $\mathrm{V}$ in positive mode, $50 \mathrm{~V}$ and $15 \mathrm{~V}$ in negative mode. An overall mass range of $50-1000 \mathrm{~m} / \mathrm{z}$ was scanned by the Orbitrap analyser and the full scan has reached a resolution of 60,000. Data-dependent acquisition (DDA) MS/MS experiments were executed with a collisionally induced dissociation (CID) scan at $30 \mathrm{eV}$ collision energy. With dynamic exclusion enabled. Dynamic exclusion was set to a repeat count of 2 and an exclusion duration was carried out $15 \mathrm{~s}$ [34].

The raw files were changed to the MzXML format (XCMS input file format) using the ProteoWizard software (V3.0.8789) [35]. The XCMS package of $\mathrm{R}$ (v3.3.2) was used for the detection of peaks, peak filtration and peak alignment [36]. Then, a twodimensional data matrix, consisting of the mass to charge ratio $(\mathrm{m} / \mathrm{z})$, retention time $(\mathrm{RT})$ and peak area of metabolites was obtained and introduced into SIMCA-P 13.0 software (Umetrics AB, Umea, Sweden) for multivariate statistical analysis [37]. Partial least squares-discriminate analysis (PLS-DA) was carried out to predict, describe modelling and discriminate variable selection [38]. Both the variable importance under the fold change (FC) values ( $\mathrm{FC} \geqq 1.5$ or $\mathrm{FC} \leqq 0.667)$ obtained from the OPLS-DA and t-test $(P<0.05)$ were engaged to analyse the differentially expressed metabolites between the two comparison 
groups [39]. Then, the precise MS/MS fragmentation information was inquired by the Human Metabolome Database (HMDB, http://www.hmdb.ca/), the Metlin database (http://metlin.scripps.edu/), KEGG (http:// www.genome.jp/kegg/) for screening and identification of potential biomarker [40, 41]. The metabolic pathways were analyzed through MetaboAnalystR 3.0 (http://www.metaboanalyst.ca).

\section{Data analysis}

Data on growth parameters and diarrhoea incidence were collected and analyzed using one-way analysis of variance (ANOVA) followed by Duncan's multiple range tests. Alpha diversity indices data was presented as "mean \pm standard deviation (SD)", and analysed by ANOVA with least significant difference (LSD) test. Employing MOTHUR (version v.1.30.1 http://www. mothur.org/) to ascertain bacterial community composition and structure. Heat map was obtained using the $\mathrm{R}$ packages VEGAN (version 3.1.0, http://www. microbesonline.org/fasttree/) [42]. Non-metric multidimensional scaling (NMDS) analysis was conducted using the VEGAN package of R (V3.1.0) software (http://www. r-project.org/). The community histograms and Venn diagrams were drawn using Origin 8.0 (OriginLab, Northampton, MA, USA). The connection between the significantly changed bacteria at the genus level and metabolites $(\mathrm{FC} \leqq 0.667$ or $\mathrm{FC} \geqq 1.5$, adjusted $P<0.05)$ were evaluated by Spearman's rho tests. Correlation maps between the body weight, diarrhea incidence, differential microbiota and metabolites were attained from the cloud platform of Gene denovo (https://www.omicshare.com/ website). Statistical calculations in the present study were based on Version 22.0 of SPSS for Windows by SPSS Inc. and a $P$ value $<0.05$ was accepted as statistically significant.

\section{Results}

\section{Growth performance}

As is shown by the data in Table 2 that no significant difference was found in the ADG, ADFI and F/G among the three treatments during each period $(P>0.05)$. One interesting finding was that diarrhoea incidence was significantly greater in the $\mathrm{PC}$ and $\mathrm{CB}$ group than $\mathrm{NC}$ group during the 14-21 day feeding $(P<0.05)$. No difference in the diarrhoea incidence was noted during the intervals of $0-7$ day, $7-14$ day and $0-21$ day $(P>0.05)$. (Table 2).

\section{Bacterial community structure}

A amount of 1,225,756 paired-end reads, including 307, 664,756 bp were produced by the raw data, and 368,348 valid sequences remained after chimaeras were filtered out and low-quality sequences were eradicated. Microbial diversity indexes are displayed in Table 3. A total of 463
Table 2 Effects of C. butyricum on growth performance and diarrhoea incidence in weaned piglets

\begin{tabular}{|c|c|c|c|c|c|}
\hline \multirow[b]{2}{*}{ Item $^{a}$} & \multicolumn{3}{|c|}{ Treatments $^{\mathbf{b}}$} & \multirow[b]{2}{*}{$\mathrm{SEM}^{3}$} & \multirow[b]{2}{*}{$P$-value } \\
\hline & $\mathrm{NC}$ & PC & $\mathrm{CB}$ & & \\
\hline Initial weight (kg) & 6.19 & 6.09 & 6.38 & 0.08 & 0.352 \\
\hline Final weight (kg) & 13.08 & 13.13 & 13.40 & 0.23 & 0.862 \\
\hline \multicolumn{6}{|l|}{ d $0-7$} \\
\hline $\mathrm{ADG}(\mathrm{g})$ & 151.36 & 171.09 & 161.22 & 5.36 & 0.370 \\
\hline ADFI(g) & 232.65 & 232.65 & 226.87 & 1.41 & 0.150 \\
\hline$F / G$ & 1.54 & 1.38 & 1.41 & 0.05 & 0.361 \\
\hline Diarrhea incidence (\%) & 10.20 & 9.52 & 6.12 & 1.95 & 0.717 \\
\hline \multicolumn{6}{|l|}{ d 7-14 } \\
\hline $\mathrm{ADG}(\mathrm{g})$ & 360.20 & 313.61 & 325.85 & 9.73 & 0.115 \\
\hline ADFI(g) & 380.27 & 382.31 & 358.16 & 8.86 & 0.531 \\
\hline$F / G$ & 1.07 & 1.22 & 1.10 & 0.04 & 0.342 \\
\hline Diarrhea incidence (\%) & 15.99 & 9.52 & 2.38 & 3.84 & 0.403 \\
\hline \multicolumn{6}{|l|}{ d 14-21 } \\
\hline $\mathrm{ADG}(\mathrm{g})$ & 472.45 & 521.43 & 516.33 & 10.76 & 0.109 \\
\hline ADFI(g) & 580.27 & 581.97 & 567.69 & 5.87 & 0.620 \\
\hline$F / G$ & 1.23 & 1.12 & 1.10 & 0.03 & 0.125 \\
\hline Diarrhea incidence (\%) & $4.08^{b}$ & $11.22^{\mathrm{a}}$ & $9.86^{\mathrm{a}}$ & 1.37 & 0.047 \\
\hline \multicolumn{6}{|l|}{ d $0-21$} \\
\hline $\mathrm{ADG}(\mathrm{g})$ & 328.00 & 335.37 & 334.47 & 10.05 & 0.961 \\
\hline ADFl(g) & 397.73 & 398.98 & 384.24 & 4.96 & 0.463 \\
\hline$F / G$ & 1.22 & 1.20 & 1.18 & 0.04 & 0.930 \\
\hline Diarrhea incidence (\%) & 10.09 & 10.09 & 6.12 & 1.85 & 0.663 \\
\hline
\end{tabular}

${ }^{\mathrm{a} A D G}$, average daily gain; $\mathrm{ADFI}$, average daily feed intake; $\mathrm{F} / \mathrm{G}$, feed to gain ratio. ${ }^{b}$ Piglets were fed different diets. NC, negative control, control diet; $\mathrm{PC}$, positive control, control diet $+0.1 \mathrm{~g} / \mathrm{kg}$ antibiotic (colistin sulphate); $C B$, control diet $+5 \times 10^{8} \mathrm{CFU} / \mathrm{kg}$ of $\mathrm{C}$. butyricum. ${ }^{3} \mathrm{SEM}$, total standard error of means. $(n=6)$

OTUs were identified from all groups. The coverage of the three treatments was above $99 \%$, demonstrating that the sequencing reads were sufficient for this analysis. OTUs and statistical estimates of the species diversity [25] and richness (ACE, Chao) for each treatment at a genetic distance of $3 \%$ are shown in Table 3. A closer inspection of the Table 3 shows that the $\mathrm{CB}$ group exhibited a significantly high OTU $(P=0.03, P=0.029)$ and a significantly high index of ACE $(P=0.036, P=0.044)$, in comparison to the NC and PC groups. The Shannon index of the $\mathrm{CB}$ group showed an increasing tendency compared to that in the NC and PC groups $(P=0.064, P=0.07)$, but none of these differences was statistically significant. In addition, the $\mathrm{CB}$ group had a significantly greater Chao index value than the NC group $(P=0.045)$. Overall, these results indicate that the $\mathrm{CB}$ treatment improved the rectal bacterial richness and diversity. (Table 3). 
Table 3 Alpha diversity indices of rectal bacterial communities in weaned piglets

\begin{tabular}{lllll}
\hline \multicolumn{5}{c}{ Treatments $^{\mathrm{a}}$} \\
\hline Item & NC & PC & CB & P-value \\
OTUs & $293.00 \pm 45.53^{\mathrm{b}}$ & $292.67 \pm 49.22^{\mathrm{b}}$ & $386.00 \pm 18.08^{\mathrm{a}}$ & 0.046 \\
Coverage, \% & $99.85 \pm 0.02$ & $99.82 \pm 0.04$ & $99.84 \pm 0.02$ & 0.523 \\
Shannon & $3.69 \pm 0.33$ & $3.70 \pm 0.30$ & $4.19 \pm 0.13$ & 0.107 \\
ACE & $318.21 \pm 42.67^{\mathrm{b}}$ & $323.38 \pm 53.71^{\mathrm{b}}$ & $408.63 \pm 19.60^{\mathrm{a}}$ & 0.062 \\
Chao & $321.21 \pm 38.30^{\mathrm{b}}$ & $332.74 \pm 59.09^{\mathrm{ab}}$ & $409.18 \pm 22.09^{\mathrm{a}}$ & 0.087
\end{tabular}

${ }^{a}$ Piglets were fed different diets. $\mathrm{NC}$, negative control, control diet; $\mathrm{PC}$, positive control, control diet $+0.1 \mathrm{~g} / \mathrm{kg}$ antibiotic (colistin sulphate); $C B$, control diet $+5 \times 10^{8} \mathrm{CFU} / \mathrm{kg}$ of $C$. butyricum. Values are represented as mean $\pm \mathrm{SD}$ $(n=3)$, and the variant letter in the same row indicated significant difference when $P<0.05$

\section{Specific microbial phyla and genera among different feeding methods}

The bacterial community composition in rectal contents at the phylum and genus level is presented in Fig. 1. There were three phyla with the abundance of $\geqq 0.01 \%$ in each group, including Bacteroidetes, Firmicutes, and Tenericutes. Bacteroidetes and Firmicutes accounted for a relative abundance of $48.77 \sim 61.85 \%$ and $36.86 \sim$ $47.62 \%$, respectively, followed by Tenericutes at $0.62 \sim$ $2.94 \%$. In comparison to the NC group, the abundance of Bacteroidetes was significantly declined in the $\mathrm{CB}$ group $(P=0.05)$ (Fig. 1b), there was a rising trend of Firmicutes in the $\mathrm{CB}$ group $(P=0.065)$. At the genus level, 128 genera were classified and the abundance of 26 of these genera was $\geqq 0.01 \%$. The relative abundance of Prevotella_9 in the $\mathrm{NC}, \mathrm{PC}$ and $\mathrm{CB}$ groups was $38.77,33.51$ and $20.42 \%$, respectively. The relative abundance of Lactobacillus was $6.80,10.30$, and $11.61 \%$, respectively. The relative abundance of Bacteroidales_S24-7_group was $3.99,3.32,6.70 \%$, respectively. The relative abundance of Megasphaera was 1.11, 4.32, 7.22\%, respectively. In contrast to the NC group, the relative abundance of Prevotella_9 showed a tendency to decrease in the CB group $(P=0.067)$. Comparing with the NC group, Megasphaera, Ruminococcaceae_NK4A214

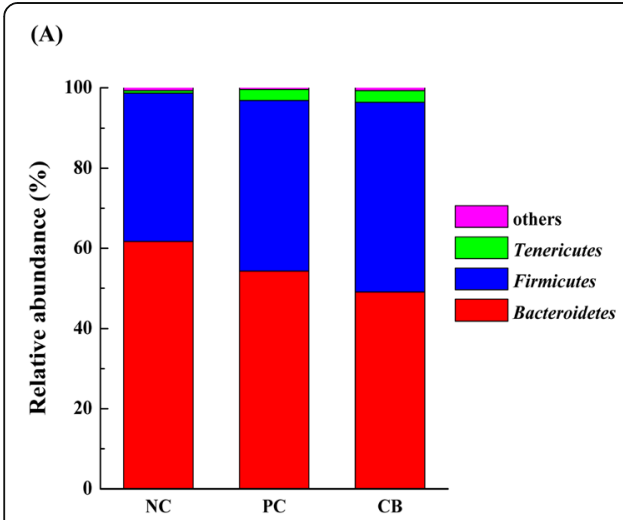

(C)

(B)
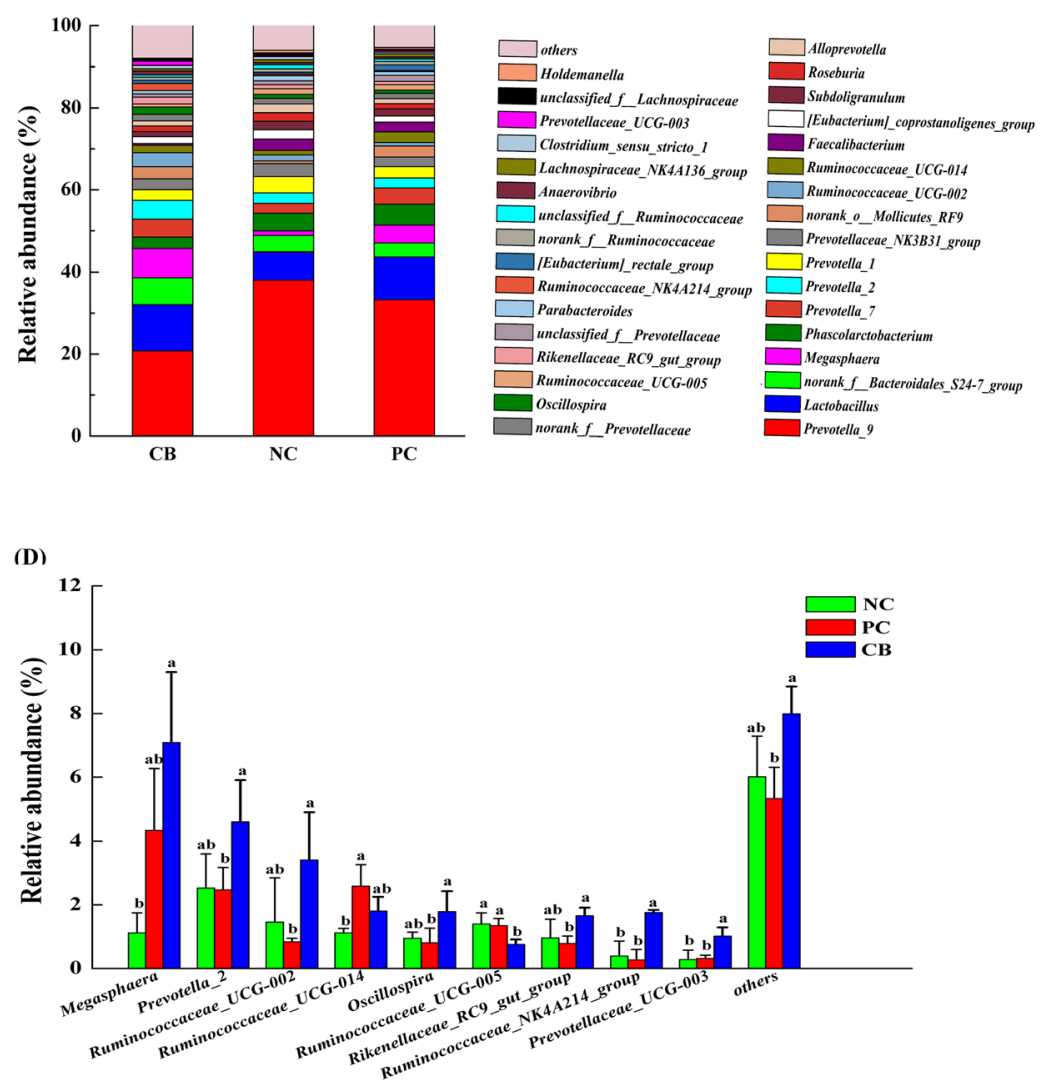

Fig. 1 Classification of the bacterial community composition across the three different treatment groups. a Relative abundance of bacterial phylum level. b Extended error bar plot showing the bacteria at the phylum level that had significant differences among the three groups. $\mathbf{c}$ Relative abundance of bacterial genus level. $\mathbf{d}$ Extended error bar plot showing the bacteria at the genus level that had significant differences among the three groups. Data presented as mean \pm standard deviation, $n=3$. Different lowercase indicates significant difference $(P<0.05)$. NC, negative control, control diet, PC, positive control, control diet $+0.1 \mathrm{~g} / \mathrm{kg}$ antibiotic (colistin sulphate), CB, control diet $+5 \times 10^{8} \mathrm{CFU} / \mathrm{kg}$ of C. butyricum 
group and Prevotellaceae_UCG-003 abundance were substantially increased in the CB group $(P<0.05)$. Prevotella_2, Ruminococcaceae_UCG-002, Oscillospira, Rikenellaceae_RC9_gut_group, Ruminococcaceae_NK4A214_ group and Prevotellaceae_UCG-003 abundance were markedly improved in the $\mathrm{CB}$ group compared with that in the PC group $(P<0.05)$. Compared with the NC group, the PC group appeared a huge increase in Ruminococcaceae_UCG-014 abundance $(P<0.05)$. The relative abundance of Ruminococcaceae_UCG-005 in CB group was significantly reduced compared with $\mathrm{NC}$ and PC groups $(P<0.05)$ (Fig. 1d).

The similarity between the bacterial communities of different treatments was confirmed by the NMDS analysis. The stress values of the NMDS differed among the phylum, genus and OTUs. A much better discrimination was observed at the genus and OTUs levels, and samples from the CB treatment clustered together, whereas other groups had no clear boundary (Fig. 2b, c). The results of the analysis of similarities demonstrate a slight descending trend between $\mathrm{NC}$ group and $\mathrm{CB}$ group, indicating that the bacterial community was sensitive to the addition of C. butyricum ( $\mathrm{R}=0.704, P=0.088$ ) (Fig. 2).

As shown in the heat map, the bacterial community of the three treatments was divided into two groups at first level (Fig. 3). One of them was composed of the $\mathrm{CB}$ group, and the other included the $\mathrm{PC}$ and $\mathrm{NC}$ groups, indicating that the bacterial community in the PC and $\mathrm{NC}$ treatments shared a high similarity and grouped into a branch apart from the CB group. (Fig. 3).

\section{LC-MS analysis}

Figure 4a and c show the PLS-DA model that was used for dimensionality reduction analysis. Each point in the figure represents a sample and a PLS-DA model was obtained, with $\mathrm{R} 2 \mathrm{X}[1]=0.255, \mathrm{R} 2 \mathrm{X}[2]=0.105$ (positive mode ionization), and R2X [1] $=0.255$, R2X [2] $=0.103$ (negative mode ionization). To reduce the intra-group differences and further expand the differences between the groups, a supervised OPLS-DA analysis was used. As shown in Fig. 4b and d, the model parameters were R2X $[1]=0.185$, R2X[XSide Comp.1] $=0.173$ (positive mode ionization), and R2X [1]=0.185, R2X[XSide Comp.1] = 0.172 (negative mode ionization). All the score plots of the faecal metabolites were carried out in the 95\% Hotelling's T2 ellipse and separated evidently. The results indicated that the model's discrimination and prediction rate were good. The scattered point map constructed by the score plots showed that the two groups exhibited a certain separation, thereby proving that the differences in composition and concentration of the variables/molecules contained in the sample were greater. (Fig. 4).

\section{Metabolite content change}

Student's t-test was accustomed to test the difference of faecal metabolites in the control (NC) group and the C. butyricum (CB) group. A $P$-value $<0.05$ and $\mathrm{FC} \geqq 1.5$ or $\mathrm{FC} \leqq 0.667$ was considered as the evidence of significant differences. It can be seen from Table 4 that 22 differential metabolites were achieved by qualitative comparison of mass spectrometry. Among them, 15 metabolites (citrulline, acetyl-DLvaline, L-citrulline, 4-hydroxy-L-proline, cimaterol, sebacic acid, suberic acid, azelaic acid, dodecanedioic acid, $o$-toluic acid, 3-methylglutaric acid, Indole-3-carboxylic acid, 4acetamidobutanoic acid, nonic acid and 2-phenylpropionic acid) were enriched. Seven metabolites (L-valine, Nacetylhistamine, phosphatidylinositol lyso 16:0, phosphatidylethanolamine lyso 18:2, trans-3-coumaric acid, xanthurenic acid and 2,3-dihydroxybenzoic acid) were decreased in the pigs fed with $C$. butyricum diet compared with the control diet. Besides, nine metabolites belonged to organic acids including O-toluic acid, 3-methylglutaric acid, indole-3carboxylic acid, 4-acetamidobutanoic acid, nonic acid, trans3-coumaric acid, xanthurenic acid, 2,3-dihydroxybenzoic acid and 2-phenylpropionic acid. Five metabolites involved in amino acid were identified to be citrulline, acetyl-DL-valine, L-citrulline, L-valine and 4-hydroxy-L-proline. Six metabolites were classified into lipids, viz. phosphatidylinositol lyso
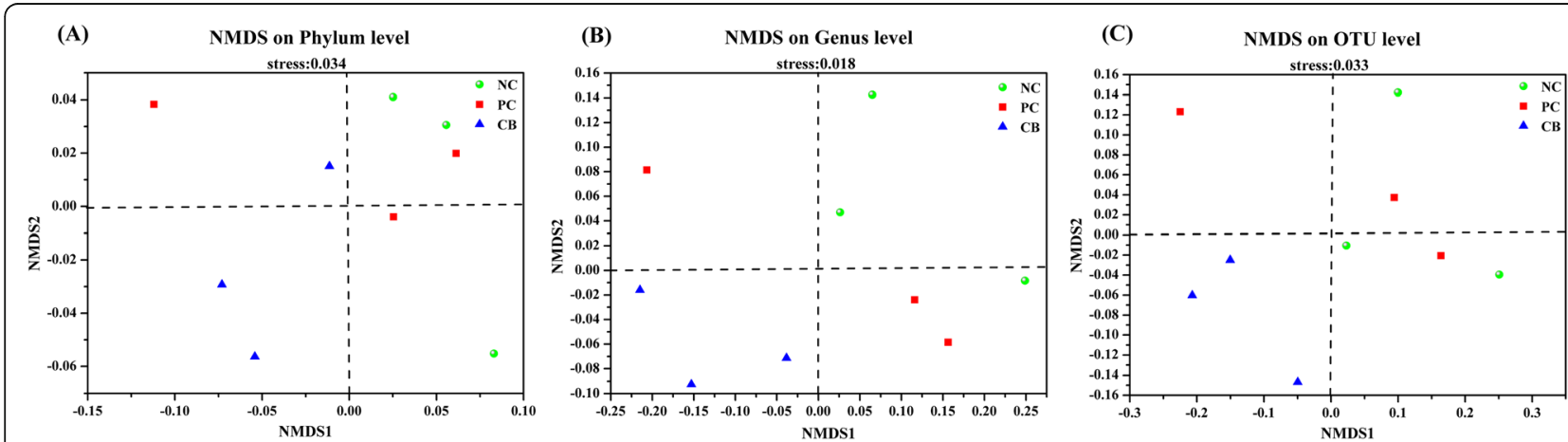

Fig. 2 Results from NMDS unconstrained ordinations of samples based on the unweighted Uni Frac distances at phylum, genus and OTU levels. a Based on phylum distribution. b Based on genus level information. c Based on total OTU distribution 


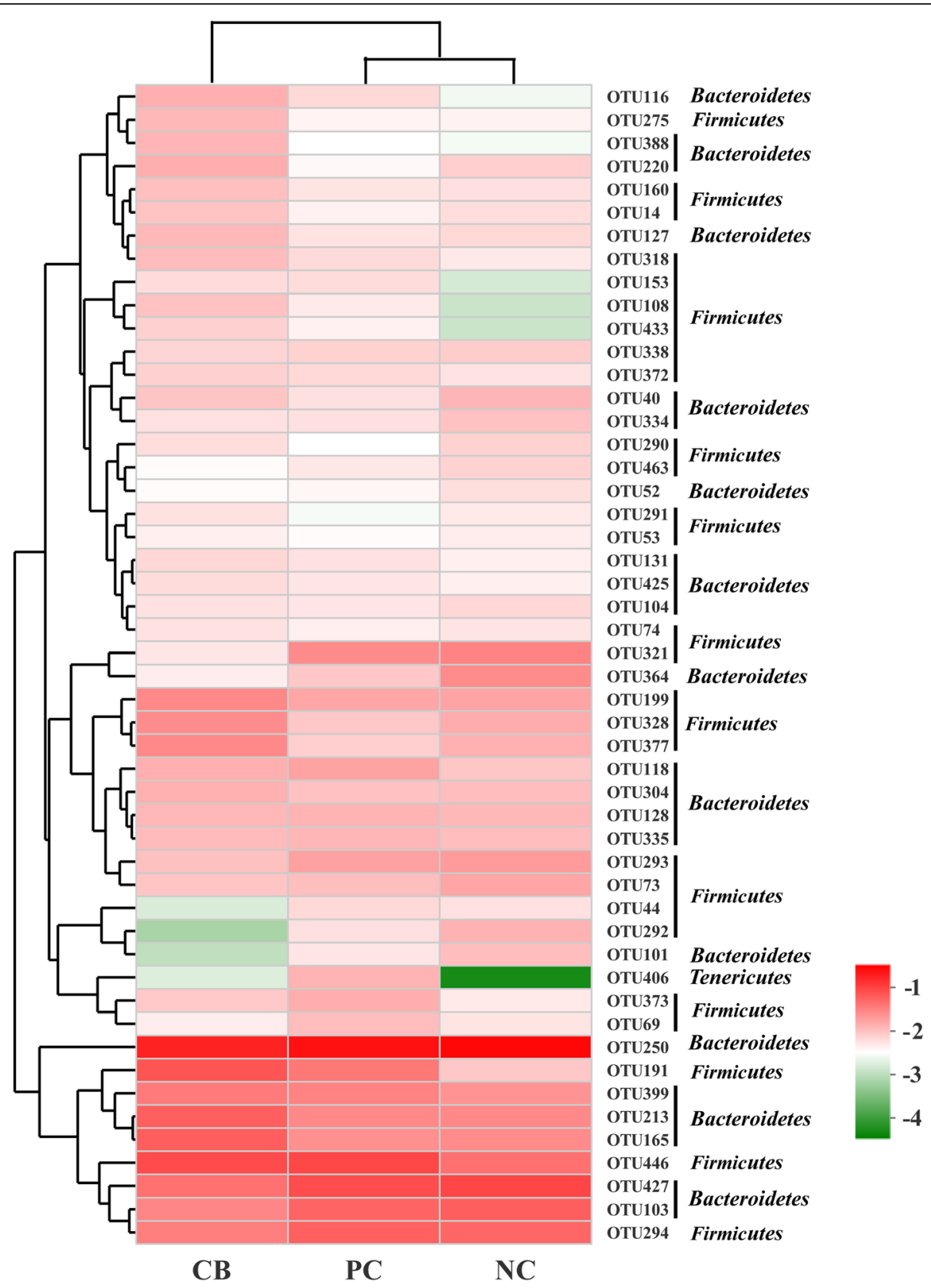

Fig. 3 Heatmap showing the most relative abundance of dominant bacterial OTUs. The relative values are indicated by color intensity with the legend indicated at the right corner

16:0, sebacic acid, suberic acid, azelaic acid, dodecanedioic acid and phosphatidylethanolamine lyso 18:2. Moreover, cimaterol and $\mathrm{N}$-acetylhistamine were classified into drugs and an amine, respectively. (Table 4).

\section{Metabolic pathway analysis}

As shown in Fig. 5, pathway enrichment map analysis of differential metabolites in faeces between $\mathrm{NC}$ and $\mathrm{CB}$ groups using MetaboAnalystR 3.0. The differential metabolites between $\mathrm{NC}$ and $\mathrm{CB}$ groups were related to three pathways, including arginine and proline metabolism; valine, leucine and isoleucine biosynthesis; and phenylalanine metabolism. (Fig. 5).

\section{Realation in the growth performance, gut microbiota and metabolites}

The results of the Spearman correlation analysis are shown in Fig. 6. Different degrees of association was observed between the growth performance, the differential microbial genera and faecal metabolites as follows: 


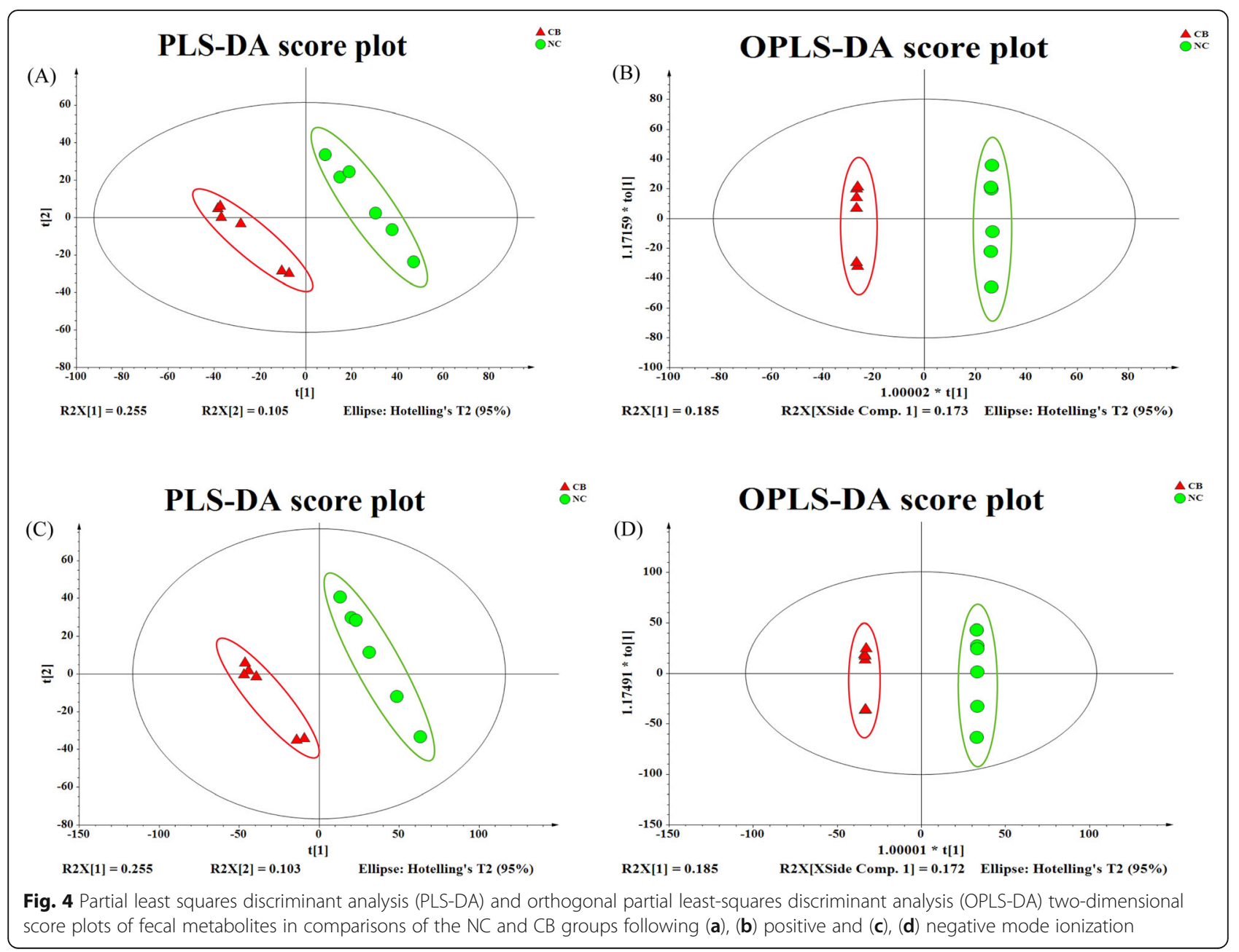

diarrhea incidence was positively associated with Ruminococcaceae_UCG-005 $(P<0.05)$, while negatively associated with Prevotella_2, Oscillospira and Ruminococcaceae NK4A214_group $(P<0.05)$ (Fig. 6a). Diarrhea incidence was positively associated with xanthurenic acid $(P<0.05)$, while negatively associated with 2-phenylpropionic acid, 4acetamidobutanoic acid, indole-3-carboxylic acid, $o$-toluic acid and citrulline $(P<0.05)$. Body weight was positively associated with 4-hydroxy-L-proline $(P<0.05)$ (Fig. 6b). Megasphaera was positively associated with citrulline, Lcitrulline, azelaic acid, nonic acid and acetyl-DL-valine $(P<0.05)$, while negatively connected with phosphatidylethanolamine lyso 18:2 $(P<0.05)$. Prevotella_2 was positively associated with 2-phenylpropionic acid, 3methylglutaric acid, $o$-toluic acid, indole-3-carboxylic acid, citrulline, L-citrulline, suberic acid $(P<0.05)$, while negatively associated with xanthurenic acid $(P<0.05)$. Ruminococcaceae_NK4A214_group was positively associated with 2-phenylpropionic acid, 3-methylglutaric acid, $o$-toluic acid, dodecanedioic acid, sebacic acid, citrulline, L-citrulline, suberic acid $(P<0.05)$. Oscillospira was positively associated with 3-methylglutaric acid, o-toluic acid, citrulline, Lcitrulline, suberic acid, 4-acetamidobutanoic acid, azelaic acid, nonic acid $(P<0.05)$, while negatively associated with xanthurenic acid $(P<0.05)$. Ruminococcaceae_UCG-002 was positively associated with 3-methylglutaric acid, $o$-toluic acid, indole-3-carboxylic acid $(P<0.05)$, while negatively associated with 2,3-dihydroxybenzoic acid and $\mathrm{N}$ acetylhistamine $(P<0.05)$. Rikenellaceae_RC9_gut_group was positively associated with 3-methylglutaric acid, cimaterol, dodecanedioic acid, sebacic acid $(P<0.05)$, while negatively associated with $\mathrm{N}$-acetylhistamine $(P<0.05)$. Prevotellaceae_UCG-003 was positively associated with a number of metabolites, including 3-methylglutaric acid, $o$ toluic acid, indole-3-carboxylic acid, dodecanedioic acid, sebacic acid, L-citrulline $(P<0.05)$, while negatively connected with 2,3-dihydroxybenzoic acid and $\mathrm{N}$ acetylhistamine $(P<0.05)$. Ruminococcaceae_UCG-005 was positively associated with 2,3-dihydroxybenzoic acid and phosphatidylethanolamine lyso $18: 2(P<0.05)$, while negatively connected with $o$-toluic acid, indole-3-carboxylic acid, citrulline and L-citrulline $(P<0.05)$ (Fig. 6c). 
Table 4 Different endogenous metabolites in the feces of weaned piglets after adding C. butyricum

\begin{tabular}{|c|c|c|c|c|c|c|c|}
\hline Super class & Metabolite names & Precurso type & $\mathrm{m} / \mathrm{z}^{\mathrm{a}}$ & $\mathrm{Rt}^{\mathrm{b}}$ & $\log 2 \mathrm{fc} \_\mathrm{CB} / \mathrm{NC}^{\mathrm{c}}$ & $P$-value & Trend $^{\mathrm{d}}$ \\
\hline Amino acids & Citrulline & {$[\mathrm{M}-\mathrm{H}]-$} & 174.09 & 101.75 & 1.71 & $<0.001$ & $\uparrow$ \\
\hline Amino acids & Acetyl-DL-Valine & {$[\mathrm{M}-\mathrm{H}]-$} & 158.08 & 306.14 & 0.83 & 0.009 & $\uparrow$ \\
\hline Amino acids & L-citrulline & {$[\mathrm{M}+\mathrm{H}]+$} & 176.10 & 102.20 & 1.05 & 0.027 & $\uparrow$ \\
\hline Amino acids & L-valine & {$[\mathrm{M}-\mathrm{H}]-$} & 115.92 & 1010.69 & -0.60 & 0.034 & $\downarrow$ \\
\hline Amino acids & 4-hydroxy-L-proline & {$[\mathrm{M}-\mathrm{H}]-$} & 129.98 & 207.29 & 0.80 & 0.044 & $\uparrow$ \\
\hline Drugs & Cimaterol & {$[\mathrm{M}+\mathrm{H}]+$} & 220.15 & 565.94 & 0.95 & 0.012 & $\uparrow$ \\
\hline Amine & $\mathrm{N}$-acetylhistamine & {$[\mathrm{M}-\mathrm{H}]-$} & 152.08 & 778.56 & -2.04 & 0.011 & $\downarrow$ \\
\hline Lipids & Phosphatidylinositol lyso $16: 0$ & {$[\mathrm{M}-\mathrm{H}]-$} & 571.29 & 738.01 & -3.50 & 0.001 & $\downarrow$ \\
\hline Lipids & Sebacic acid & {$[\mathrm{M}-\mathrm{H}]-$} & 201.11 & 561.47 & 1.42 & 0.001 & $\uparrow$ \\
\hline Lipids & Suberic acid & {$[\mathrm{M}-\mathrm{H}]-$} & 173.08 & 452.26 & 1.19 & 0.011 & $\uparrow$ \\
\hline Lipids & Azelaic acid & {$[\mathrm{M}-\mathrm{H}]-$} & 187.10 & 508.95 & 1.38 & 0.019 & $\uparrow$ \\
\hline Lipids & Dodecanedioic acid & {$[\mathrm{M}-\mathrm{H}]-$} & 229.14 & 657.55 & 0.72 & 0.024 & $\uparrow$ \\
\hline Lipids & Phosphatidylethanolamine lyso 18:2 & {$[\mathrm{M}-\mathrm{H}]-$} & 476.28 & 827.81 & -1.06 & 0.028 & $\downarrow$ \\
\hline Organic acids & O-toluic acid & {$[\mathrm{M}-\mathrm{H}]-$} & 135.05 & 538.95 & 1.11 & 0.002 & $\uparrow$ \\
\hline Organic acids & 3-methylglutaric acid & {$[\mathrm{M}-\mathrm{H}]-$} & 145.05 & 380.25 & 1.53 & 0.003 & $\uparrow$ \\
\hline Organic acids & Indole-3-carboxylic acid & {$[\mathrm{M}-\mathrm{H}]-$} & 160.04 & 504.67 & 1.38 & 0.014 & $\uparrow$ \\
\hline Organic acids & 4-acetamidobutanoic acid & {$[\mathrm{M}-\mathrm{H}]-$} & 144.07 & 264.59 & 1.23 & 0.015 & $\uparrow$ \\
\hline Organic acids & Nonic Acid & {$[\mathrm{M}+\mathrm{H}]+$} & 189.11 & 513.04 & 1.72 & 0.016 & $\uparrow$ \\
\hline Organic acids & Trans-3-coumaric acid & {$[\mathrm{M}-\mathrm{H}]-$} & 163.04 & 459.07 & -1.48 & 0.023 & $\downarrow$ \\
\hline Organic acids & Xanthurenic acid & {$[\mathrm{M}-\mathrm{H}]-$} & 204.03 & 464.26 & -1.39 & 0.028 & $\downarrow$ \\
\hline Organic acids & 2,3-dihydroxybenzoic acid & {$[\mathrm{M}-\mathrm{H}]-$} & 153.02 & 397.38 & -1.22 & 0.037 & $\downarrow$ \\
\hline Organic acids & 2-phenylpropionic acid & {$[\mathrm{M}-\mathrm{H}]-$} & 149.06 & 601.41 & 0.88 & 0.041 & $\uparrow$ \\
\hline
\end{tabular}

${ }^{a} \mathrm{~m} / \mathrm{z}$, mass-to-charge ratio; ${ }^{\mathrm{b}} \mathrm{RT}$, retention time; ${ }^{\mathrm{c} F C}$ fold change; ${ }^{\mathrm{d} m} \uparrow / \downarrow$ " indicate the increase/decrease in the metabolite level after adding C. butyricum to the diet $(n=6)$

\section{Discussion}

Increasing evidences suggest the opinion that probiotics can enhance animal growth [43-45]. The application of C. butyricum as a feed additive in animals has been widely proven [14, 20, 46, 47]. However, there is a shortage of information on the microbial community and the metabolic profile, after the addition with $C$. butyricum in the feed in weaned piglets. In the current study, we investigated the microbiota diversity and metabolite profiles of weaned piglets fed C. butyricum using 16S rRNA MiSeq sequencing and LC-MS/MS. Our results showed that the intestinal microbial community and metabolic profiles were significantly different in piglets fed $C$. butyricum compared with control diet pigs.

Several reports have shown that C. butyricum-based probiotics exhibited a significant positive influence on growth performance in weaned piglets [13, 48]. It has been reported that $C$. butyricum addition to the diet led to an increase in the villus height and enlarged crypt depth, which points out that the absorptive capacity of the intestinal cells was raised and possibly contributing an improvement in the average daily gain. Another report pointed out that the reason for the reduction of diarrhea incidence was the production of butyric acid by C. butyricum. The production of butyrate in the colon inhibited the fatty acid synthesis, which resulted in the production of folic acid, and because of the role of folic acid in methylation and gene regulation, diarrhoea was reduced [49]. However, in this study, the addition of $C$. butyricum to the diet did not significantly affect the growth performance of the piglets. One unanticipated finding was that diarrhea incidence was significantly taller in the antibiotic addition group and C. butyricum addition group than that in the control group during 14-21 day feeding. A possible reason may depend on the amount of the antibiotics and C. butyricum additive, gut microbiota, environmental conditions and health status of the piglets, suggesting that a small stress was more likely to cause diarrhea in piglets treated with antibiotics and $C$. butyricum, before the stabilization of the intestinal microbial colonies.

As an imperative part of the intestinal tract, the intestinal microbiota is also known as the body's black box. All life activities and metabolism, barrier function, nutrition, and immune response are closely related to human health [50]. The steady-state of the flora has an 


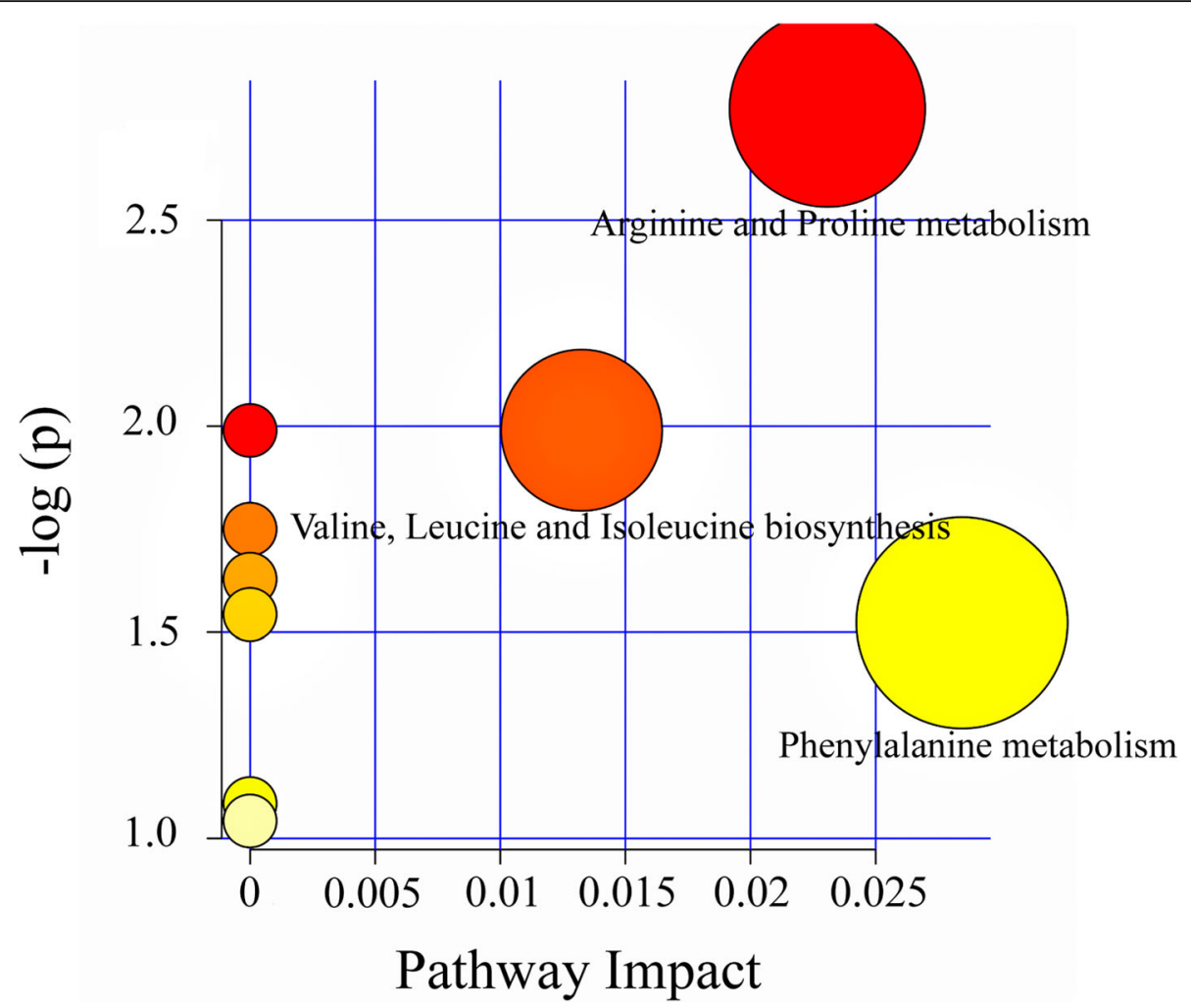

Fig. 5 Pathway enrichment map analysis of differential metabolites in faeces between NC and CB groups using MetaboAnalystR 3.0. The colour of the circles from white to yellow to red denotes incremental fold change $(-\log (p))$. The size of the circles from small to large indicates an increment of the impact of pathway

important influence on maintaining the body's growth and development, nutrient digestion and absorption, and immune antagonism [51]. A richer microbiota composition readily reduces the incidence of disease and affects the health of the host [52]. Many researchers have reported that the guiding phyla in the gastrointestinal tract are Firmicutes and Bacteroidetes in pig fecal samples [44, 53, 54] and our results supported this. Firmicutes comprises a range of cellulolytic organisms, which are advantageous to cellulose decomposition [55]. Bacteroides can degrade high-molecular-weight organic matter and improve the innate immune response by enhancing the function of intestinal mucosal barrier [56, 57]. A huge number of investigations have shown that probiotic intervention can change the structure of intestinal flora by regulating the ratio of Firmicutes/Bacteroidetes [58] and Proteobacteria/Bacteroidetes [59]. Prior research indicated that there was a correlation between body weight and gut microbial ecology. The microbiota in obese subjects indicated an elevatory proportion of Firmicutes and a depressed population of Bacteroides. Likewise, an amplified Firmicutes/Bacteroidetes ratio has been directly linked to weight gain [60]. More studies have shown that the raise in Firmicutes with the decrease of Bacteroidetes in gut exert exhibited a strong connection with host lipid accumulation and fatty liver $[20,61,62]$. Our study identified that Bacteroidetes, Firmicutes and Tenericutes were found to be the dominant flora in the intestinal tract of piglets. Diets supplemented with $C$. butyricum showed a trend of increasing the ratio of Firmicutes/Bacteroidetes $(P=0.075)$. All this indicates that $C$. butyricum has the potential to promote the growth of piglets by increasing the Firmicutes/Bacteroidetes ratio.

Prevotella is the most abundant microorganism in the Bacteroidetes group, and it is an exceedingly active hemicellulose-decomposing bacterium that is essential for the degradation of plant non-fibrous polysaccharides and proteins [63, 64]. Megasphaera elsdenii is a major inhabitant of the pig intestine [65] and is a predominant and important bacteria that converts lactate to all sorts of short chain fatty acids (SCFAs), such as acetate, propionate, butyrate and valerate [54]. These SCFAs functions as an energy source for the host and plays a momentous role in gut health [66]. It has been reported that Megasphaera improved the gastrointestinal health of rats [67] and pigs [68] as a probiotic treatment. Some research indicated that C. butyricum enhanced the uniformity of the intestinal bacterial community and maintained a more balanced microbial structure in the weaned piglets. Megasphaera increased from 3.79 to $11.31 \%$ and became the main 
(A)

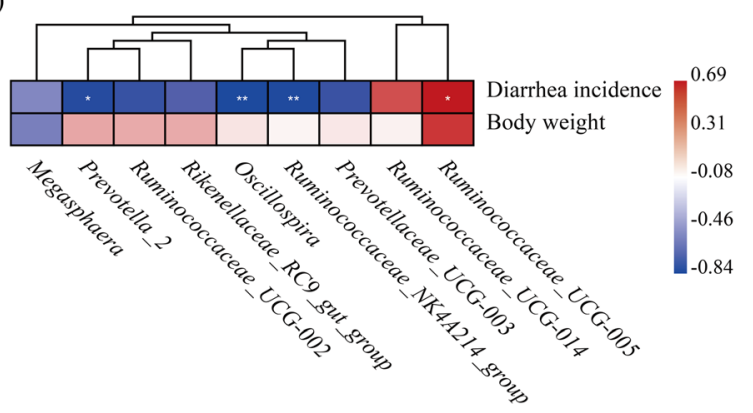

(B)

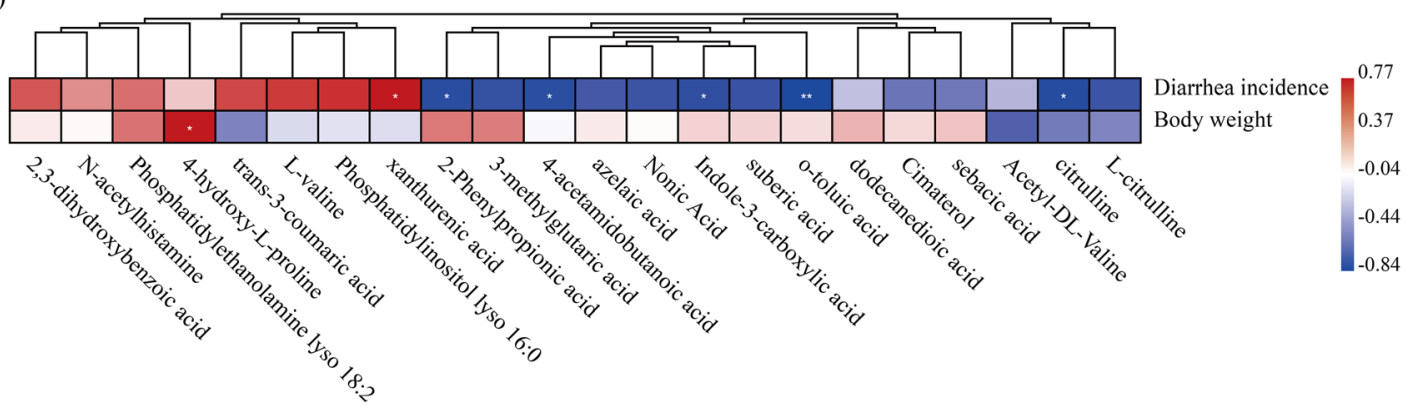

(C)

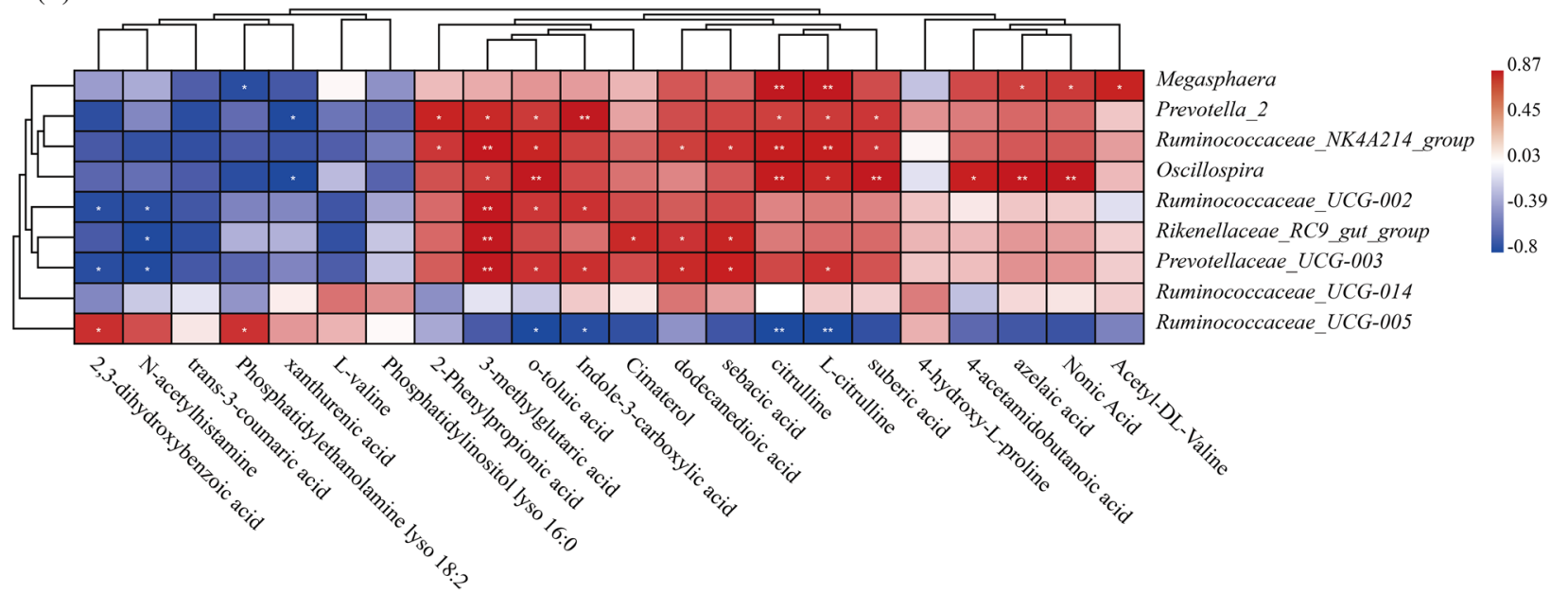

Fig. 6 Correlation between the body weight, diarrhea incidence, differential microbiota (at the genera level) and metabolites. a Correlation between body weight, diarrhea incidence and microbiota. b Correlation between body weight, diarrhea incidence and metabolites. c Correlation between microbiota and metabolites. Strength (Spearman's $\rho$ value) and significance of correlations are shown as color in shades (red, positive correlation; blue, negative correlation). The values above/below zero represent positive/negative correlations. Significant correlations are noted by * $P<0.05,{ }^{*} P<0.01$

responder [54]. Similar to these consequences, the current researches presented that $C$. butyricum greatly improved the abundance of Megasphaera. Ruminococcaceae, a member of the Firmicutes, is one of the most abundant families in the order Clostridiales, which is associated with the maintenance of gut health [69]. It is reported that they primarily produce butyric acid that exerts probiotic physiological functions in the gut $[70,71]$. Both Ruminococcaceae_UCG-002 and Ruminococcaceae_UCG-014 genera produce butyrate, which plays a dominant role in the colon health [70,72]. Our investigations indicate that diet added with $C$. butyricum can enhance the relative proportion of Megasphaera and Ruminococcaceae NK4A214_group, thereby enhancing the superior position of the Firmicutes in the intestinal flora. Oscillospira species are producers of butyrate, and at least some of them can utilize glucuronate [73]. A study shows that Oscillospira improved the metabolism [74] and had the ability to 
degrade host glycans [75]. In the present study, it was perceived that $C$. butyricum substantially. Increased the relative abundance of the genus Oscillospira. This suggests that $C$. butyricum can promote the metabolism by improving Oscillospira abundance. This indicates that $C$. butyricum can promote the metabolism by improving Oscillospira abundance. The results of correlation analysis illustrated that the abundance of Prevotella_2, Oscillospira and Ruminococcaceae_NK4A214_group were negatively correlated with the diarrhea incidence, Ruminococcaceae UCG-005 was positively associated with diarrhea incidence, indicating that the relative abundance of Prevotella_2, Oscillospira, Ruminococcaceae_NK4A214_group and Ruminococcaceae_UCG-005 were important intestinal fecal bacteria, which closely related to the diarrhea.

Metabonomics has been labelled as one of the new '-omics', joining genomics, transcriptomics and proteomics as a science employed for the understanding of global systems biology [76]. Metabonomics has been widely applied in many research areas, including drug toxicology [77], biomarker discovery [78], functional genomics [79], molecular pathology [80] and animal nutrition [81]. Similarly to other omics, the subtle changes in metabolite content are directly related to large changes in biological phenotype [82]. Previous research has shown that C. butyricum might be a practicable probiotic to decrease the saturated fatty acids contents and increase the monounsaturated fatty acids and polyunsaturated fatty acids contents of Peking duck meat [83].

Citrulline is a common intermediate metabolic molecule in mammals. It is an amino acid that is not involved in protein synthesis, but is closely related to arginine metabolism [84]. In the current study, the levels of citrulline and L- citrulline in the metabolites were significantly increased in the faeces of the piglets with C. butyricum supplemented diet. One interesting finding was that the content of citrulline in faecal metabolites was positively associated with the abundance of Megasphaera, Prevotella_2, Ruminococcaceae_NK4A214_group, Oscillospira, while negatively correlated with the diarrhea incidence and Ruminococcaceae_UCG-005 in faecal microorganisms. Comprehensive analysis of bacteria in the genus, we conclude that $C$. butyricum mainly increases the content of citrulline in faecal metabolites by increasing Megasphaera, Ruminococcaceae_NK4A214_group and decreasing the abundance of Ruminococcaceae_UCG-005.

Valine is one of the most important essential amino acid in pigs, and belongs to branched-chain amino acids [85]. It is a glycemic amino acid [86]. After transamination, oxidative decarboxylation and dehydrogenation, succinic monoacyl CoA is produced, which enters into the tricarboxylic acid cycle and supplies energy to the body. In this study, the amount of L-valine was decreased and acetyl-DL-valine was increased by $C$. butyricum treatment, which may contribute to the disturbance of valine metabolism. 3-Methylglutaric acid is a metabolite derived from leucine catabolism [87]. In our research, an increase in the level of 3-methylglutaric acid indicates the changes in leucine metabolism.

The significance of proline has been extensively exhibited to act a pivotal part in cell structure, anti-oxidative reactions, immune responses, energy metabolism and protein synthesis in more plentiful organisms [88]. The addition of proline to the standard abalone diets has been found to act as a substrate for the amino acid catabolism in slower-growing abalone, to utilize the decomposition of proline to aid in the generation of energy through the tricarboxylic acid cycle [89]. In our study, dietary C. butyricum increased the levels of 4-hydroxyL-proline and 4-hydroxy-L-proline was positively correlated with body weight, suggesting that the proline metabolism pathway was disturbed.

Cimaterol is a kind of beta doping. In animal husbandry production, a large dose of cimaterol can reduce the fat content of the carcass, improve the proportion of lean meat, promote the growth of livestock and achieve the effect of improving meat quality [90, 91]. Histamine plays a very significant role in the various physiological function of immune, nervous and gastrointestinal systems. There have been reports that histamine is associated with secretion of gastric acid in the gastrointestinal system [92]. In our study, dietary C. butyricum decreased the levels of the $\mathrm{N}$-acetylhistamine and the content of $\mathrm{N}$-acetylhistamine was negatively correlated with the abundance of Ruminococcaceae_UCG-002, Rikenellaceae_RC9_gut_group, and Prevotellaceae_UCG-003. This finding suggests that $C$. butyricum could cause the abnormal histidine metabolism, alongwith an abundance of beneficial bacteria in the gut.

Suberic acid is a colorless crystalline dibasic acid. It has been reported that a great potential exists for suberic acid to be developed as an anti-photoaging agent [93]. Azelaic acid is a natural saturated dicarboxylic acid that is useful for the treatment of comedonal acne and inflammatory acne [94]. Dodecanedioic acid is a dicarboxylic acid with 12 carbon atoms. It has not been confirmed for intestinal absorption, but has been indicated hepatic and renal uptake [27]. In the present study, medium-chain dicarboxylic acids (suberic and azelaic acid) and long-chain dicarboxylic acids (sebacic acids, dodecanedioic acid) were improved in the C. butyricum addition group as compared with the control group. This showed that C. butyricum enhances the fatty acid oxidation in piglets. Moreover, sebacic acids and dodecanedioic acid were found to be associated positively with Ruminococcaceae_NK4A214_group, Rikenellaceae_RC9_ gut_group and Prevotellaceae_UCG-003. Suberic was associated positively with Prevotella_2, Ruminococcaceae_ 
NK4A214_group, Oscillospira. Azelaic acid was associated positively with Megasphaera and Oscillospira. In this pursuit, we suggest that the gut microbiota has a large metabolic potential and can impact the host's nutrition significantly. Recent studies have further reinforced that gut microbiota affects host health and disease [27].

Indole-3-acetic acid is a metabolite of tryptophan, which is mainly produced by direct or indirect metabolism of the intestinal microbiota [95]. About $4-6 \%$ of tryptophan is degraded by bacteria to produce indole metabolites [96]. Other studies have suggested that indole, a microbial breakdown product of tryptophan, regulate the integrity of intestinal tight junctions [97]. It was proposed that indol metabolites and their gut bacterial producers play an important role in overweight related inflammation in young adults [98]. Our results showed that indole-3carboxylic acid was upregulated and the content of indole-3-carboxylic acid was positively correlated with the abundance of Prevotella_2, Ruminococcaceae_UCG-002, Prevotellaceae_UCG-003, while negatively correlated with diarrhea incidence and Ruminococcaceae_UCG-005 abundance, suggesting that $C$. butyricum can affect the growth health of piglets by regulating the indolic tryptophan metabolic pathway. Xanthine acid is one of several metabolites involved in the kynurenine pathway of tryptophan metabolism [99], which promotes increased bone density and is associated with a lower risk of fracture [100]. Based on our results, it appeared that the levels of xanthurenic acid were downregulated and the content of xanthurenic acid was positively correlated with diarrhea incidence, while negatively associated with the abundance of Prevotella_2 and Oscillospira. An earlier study has demonstrated that there was reciprocal relationship between gut microbes and several bacterial metabolites that facilitates changes in intestinal homeostasis [101].

\section{Conclusions}

In the present study, we examined the overall comprehension of the patterns of microbial colonization and metabolite composition in healthy piglets using C. butyricum as a feed additive. Our results demonstrate that the shift of the fecal microbiome composition and concentration, and the colonization of potential probiotics was accelerated by $C$. butyricum, which may modulate the host metabolism and enhance the intestinal development. Furthermore, Spearman's analysis revealed an obvious correlation between the microbiota and the metabolites, indicating that $C$. butyricum presented the potential protective impact through gut microbiota and other pathways.

\section{Authors' contributions}

Wen-Ju Zhang and Cunxi Nie conceived and designed the whole trial and contributed funding. Jing Liang, Shasha Kou and Cheng Chen designed the conceptualization and performed the experiments. Sayed Haidar Abbas Raza and Sihu Wang conducted partial data analyses. The manuscript was written by Jing Liang, and was modified by Xi Ma, Wen-Ju Zhang and Cunxi Nie. All authors read and approved the final manuscript.

\section{Funding}

This work was supported by Grants from Bingtuan Applied Basic Research Project (2016AG009), Shihezi University Young Innovative Talents Program (CXRC201807), XPCC Science and Technology Innovation Talent Program (2020CB023).

\section{Declarations}

Ethics approval and consent to participate

All animal experiments were conducted according to the guidelines established by the regulations this work was performed at a farm in the Department of Animal Sciences and Shihezi University, Shihezi, Xinjiang PR China. Ethical approval for this study was obtained from the Ethical Committee of Shihezi University, approval number: A2018-168-01. The procedures were approved by the Ethical Committee of China Animal Care Shihezi University, Shihezi, Xinjiang. Moreover, the present study has been reported in compliance with the ARRIVE guidelines (Animal Research: Reporting in Vivo Experiments).

\section{Competing interests}

The authors declare that the research wasconducted in the absence of any commercial or financial relationships that couldbe construed as a potential competing interests.

\section{Author details}

${ }^{1}$ College of Animal Science and Technology, Shihezi University, Shihezi, Xinjiang 832003, People's Republic of China. ${ }^{2}$ College of Animal Science and Technology, Northwest A\&F University, Yangling, Shaanxi 712100, People's Republic of China. ${ }^{3}$ State Key Laboratory of Animal Nutrition, College of Animal Science and Technology, China Agricultural University, Beijing 100193, People's Republic of China.

Received: 12 October 2020 Accepted: 5 March 2021

Published online: 22 March 2021

\section{References}

1. Moeser AJ, Pohl CS, Rajput M. Weaning stress and gastrointestinal barrier development: implications for lifelong gut health in pigs. Anim Nutr. 2017; 3(4):313-21. https://doi.org/10.1016/j.aninu.2017.06.003.

2. Mehdi Y, Létourneau-Montminy MP, Gaucher ML, Chorfi Y, Gayatri S, Rouissi T, Brar SK, Côté C, Ramirez AA, Godbout S. Use of antibiotics in broiler production: global impacts and alternatives. Anim Nutr. 2018;4(2):170-8. https://doi.org/10.1016/j.aninu.2018.03.002.

3. Omonijo FA, Ni L, Gong J, Wang Q, Lahaye L, Yang C. Essential oils as alternatives to antibiotics in swine production. Anim Nutr. 2018;4(2):126-36. https://doi.org/10.1016/j.aninu.2017.09.001.

4. Wan ML, Forsythe SJ, Hani EN. Probiotics interaction with foodborne pathogens: a potential alternative to antibiotics and future challenges. Critical Reviews in Food Science \& Nutrition. 2018;59(20):1-29. https://doi. org/10.1080/10408398.2018.1490885.

5. Yang $X$, Liu Y, Yan F, Yang C, Yang X. Effects of encapsulated organic acids and essential oils on intestinal barrier, microbial count, and bacterial metabolites in broiler chickens. Poult Sci. 2019;98(7):2858-65. https://doi. org/10.3382/ps/pez031.

6. Seo M, Inoue I, Tanaka M, Matsuda N, Nakano T, Awata T, Katayama S, Alpers DH, Komoda T. Clostridium butyricum MIYAIRI 588 improves high-fat diet-induced non-alcoholic fatty liver disease in rats. Dig Dis Sci. 2013;58(12): 3534-44. https://doi.org/10.1007/s10620-013-2879-3.

7. Zhang B, Yang X, Guo Y, Long F. Effects of dietary lipids and Clostridium butyricum on the performance and the digestive tract of broiler chickens. Arch Anim Nutr. 2011;65(4):329-39. https://doi.org/10.1080/1745039X.2011. 568274.

8. Hayashi A, Sato T, Kamada N, Mikami Y, Matsuoka K, Hisamatsu T, Hibi T, Roers A, Yagita H, Ohteki T, Yoshimura A, Kanai T. A single strain of Clostridium butyricum induces intestinal IL-10-producing macrophages to suppress acute experimental colitis in mice. Cell Host Microbe. 2013;13(6): 711-22. https://doi.org/10.1016/j.chom.2013.05.013. 
9. Huang T, Peng XY, Gao B, Wei QL, Xiang R, Yuan MG, Xu ZH. The effect of Clostridium butyricum on gut microbiota, immune response and intestinal barrier function during the development of necrotic enteritis in chickens. Front Microbiol. 2019;10:2309. https://doi.org/10.3389/fmicb.2019.02309.

10. Chen D, Jin D, Huang S, Wu J, Xu M, Liu T, Dong W, Liu X, Wang S, Zhong W, Liu Y, Jiang R, Piao M, Wang B, Cao H. Clostridium butyricum, a butyrateproducing probiotic, inhibits intestinal tumor development through modulating Wnt signaling and gut microbiota. Cancer Lett. 2020;469:45667. https://doi.org/10.1016/j.canlet.2019.11.019.

11. Yang CM, Cao GT, Ferket PR, Liu TT, Zhou L, Zhang L, Xiao YP, Chen AG. Effects of probiotic, Clostridium butyricum, on growth performance, immune function, and cecal microflora in broiler chickens. Poult Sci. 2012;91(9):21219. https://doi.org/10.3382/ps.2011-02131.

12. Chen L, Li S, Zheng J, Li W, Jiang X, Zhao X, Li J, Che L, Lin Y, Xu S, Feng B, Fang $Z$, de Wu. Effects of dietary Clostridium butyricum supplementation on growth performance, intestinal development, and immune response of weaned piglets challenged with lipopolysaccharide. J Anim Sci Biotechnol. 2018;9(1):62. https://doi.org/10.1186/s40104-018-0275-8.

13. Cao G, Tao F, Hu Y, Li Z, Zhang Y, Deng B. Zhan Xa. Positive effects of a Clostridium butyricum-based compound probiotic on growth performance, immune responses, intestinal morphology, hypothalamic neurotransmitters, and colonic microbiota in weaned piglets. Food Funct. 2019;10(5):2926-34. https://doi.org/10.1039/c8fo02370k.

14. Liu L, Zeng D, Yang M, Wen B, Lai J, Zhou Y, Sun H, Xiong L, Wang J, Lin Y, Pan K, Jing B, Wang P, Ni X. Probiotic Clostridium butyricum improves the growth performance, immune function, and gut microbiota of weaning rex rabbits. Probiotics Antimicrob Proteins. 2019;11(4):1278-92. https://doi.org/1 0.1007/s12602-018-9476-X.

15. Casas GA, Blavi L, Cross TL, Lee AH, Swanson KS, Stein HH. Inclusion of the direct-fed microbial Clostridium butyricum in diets for weanling pigs increases growth performance and tends to increase villus height and crypt depth, but does not change intestinal microbial abundance. J Anim Sci. 2020;98(1):98(1). https://doi.org/10.1093/jas/skz372.

16. Wang K, Chen G, Cao G, Xu Y, Wang Y, Yang C. Effects of Clostridium butyricum and Enterococcus faecalis on growth performance, intestinal structure, and inflammation in lipopolysaccharide-challenged weaned piglets. J Anim Sci. 2019;97(10):4140-51. https://doi.org/10.1093/jas/skz235.

17. Zhan HQ, Dong XY, Li LL, Zheng YX, Gong YJ, Zou XT. Effects of dietary supplementation with Clostridium butyricum on laying performance, egg quality, serum parameters, and cecal microflora of laying hens in the late phase of production. Poult Sci. 2019;98(2):896-903. https://doi.org/10.3382/ ps/pey436.

18. Miao RX, Zhu XX, Wan CM, Wang ZL, Wen Y, Li YY. Effect of supplementation on the development of intestinal flora and the immune system of neonatal mice. Exp Ther Med. 2018;15(1):1081-6. https://doi.org/1 0.3892/etm.2017.5461.

19. Liu M, Xie W, Wan X, Deng T. Clostridium butyricum modulates gut microbiota and reduces colitis associated colon cancer in mice. Int Immunopharmacol. 2020:88:106862. https://doi.org/10.1016/j.intimp.2020.106862.

20. Wang WW, Wang J, Zhang HJ, Wu SG, Qi GH. Supplemental Clostridium butyricum modulates lipid metabolism through shaping gut microbiota and bile acid profile of aged laying hens. Front Microbiol. 2020;11:600. https:// doi.org/10.3389/fmicb.2020.00600.

21. Turnbaugh PJ, Ley RE, Mahowald MA, Magrini V, Mardis ER, Gordon JI. An obesity-associated gut microbiome with increased capacity for energy harvest. Nature. 2006;444(7122):1027-31. https://doi.org/10.1038/na ture05414.

22. Anhê FF, Varin TV, Le Barz M, Desjardins Y, Levy E, Roy D, Marette A. Gut microbiota dysbiosis in obesity-linked metabolic diseases and prebiotic potential of polyphenol-rich extracts. Curr Obes Rep. 2015;4(4):389-400. https://doi.org/10.1007/s13679-015-0172-9.

23. Li Y, Guo Y, Wen Z, Jiang X, Ma X, Han X. Weaning stress perturbs gut microbiome and its metabolic profile in piglets. Sci Rep. 2018;8(1):18068. https://doi.org/10.1038/s41598-018-33649-8.

24. Smirnov KS, Maier TV, Walker A, Heinzmann SS, Forcisi S, Martinez I, Walter J, Schmitt-Kopplin P. Challenges of metabolomics in human gut microbiota research. Int J Med Microbiol. 2016;306(5):266-79. https://doi.org/10.1016/j. ijmm.2016.03.006

25. Ramsay TG, Stoll MJ, Shannon AE, Blomberg LA. Metabolomic analysis of longissimus from underperforming piglets relative to piglets with normal preweaning growth. J Anim Sci Biotechnol. 2018;9(1):36. https://doi.org/1 0.1186/s40104-018-0251-3.

26. Yu M, Li Z, Chen W, Rong T, Wang G, Ma X. Microbiome-metabolomics analysis investigating the impacts of dietary starch types on the composition and metabolism of colonic microbiota in finishing pigs. Front Microbiol. 2019;10:1143-56. https://doi.org/10.3389/fmicb.2019.01143.

27. Mercer KE, Ten Have GAM, Pack L, Lan R, Deutz NEP, Adams SH, Piccolo BD. Net release and uptake of xenometabolites across intestinal, hepatic, muscle, and renal tissue beds in healthy conscious pigs. Am J Physiol Gastrointest Liver Physiol. 2020;319(2):G133-41. https://doi.org/10.1152/ajpgi. 00153.2020 .

28. NRC. Nutrient requirements of swine. 11th ed. Washington, DC: Natl. Acad. Press; 2012. p. 127-156.

29. Liang J, Raza SHA, Kou S, Chen C, Yao M, Wu Y, Wang S, Ma X, Zhang W, Nie C. Effect of Clostridium butyricum on plasma immune function, antioxidant activity and metabolomics of weaned piglets. Livest Sci. 2020; 241:104267. https://doi.org/10.1016/j.livsci.2020.104267.

30. Quan J, Cai G, Ye J, Yang M, Ding R, Wang X, Zheng E, Fu D, Li S, Zhou S, Liu D, Yang J, Wu Z. A global comparison of the microbiome compositions of three gut locations in commercial pigs with extreme feed conversion ratios. Sci Rep. 2018;8(1):4536. https://doi.org/10.1038/s41598-018-22692-0.

31. Zheng J, Xiao X, Zhang Q, Mao L, Yu M, Xu J, Wang T. The placental microbiota is altered among subjects with gestational diabetes mellitus: a pilot study. Front Physiol. 2017:8:675. https://doi.org/10.3389/fphys.2017. 00675.

32. Wang K, Chu C, Li X, Wang W, Ren N. Succession of bacterial community function in cow manure composing. Bioresour Technol. 2018;267:63-70. https://doi.org/10.1016/j.biortech.2018.06.028.

33. Sangster T, Major H, Plumb R, Wilson AJ, Wilson ID. A pragmatic and readily implemented quality control strategy for HPLC-MS and GC-MS-based metabonomic analysis. Analyst. 2006;131(10):1075-8. https://doi.org/10.1039/ b604498k.

34. Want EJ, Wilson ID, Gika H, Theodoridis G, Plumb RS, Shockcor J, Holmes E, Nicholson JK. Global metabolic profiling procedures for urine using UPLCMS. Nat Protoc. 2010;5(6):1005-18. https://doi.org/10.1038/nprot.2010.50.

35. Smith CA, Want EJ, O'Maille G, Abagyan R, Siuzdak G. XCMS: processing mass spectrometry data for metabolite profiling using nonlinear peak alignment, matching, and identification. Anal Chem. 2006;78(3):779-87. https://doi.org/10.1021/ac051437y.

36. Jia H, Shen X, Guan Y, Xu M, Tu J, Mo M, Xie L, Yuan J, Zhang Z, Cai S, Zhu J, Zhu ZJ. Predicting the pathological response to neoadjuvant chemoradiation using untargeted metabolomics in locally advanced rectal cancer. Radiother Oncol. 2018;128(3):548-56. https://doi.org/10.1016/j.ra donc.2018.06.022.

37. Niu JL, Zhang J, Wei LQ, Zhang WJ, Nie CX. Effect of fermented cottonseed meal on the lipid-related indices and serum metabolic profiles in broiler chickens. Animals (Basel). 2019;9(11):930-49. https://doi.org/10.3390/ani911 0930.

38. Lee LC, Liong C-Y, Jemain AA. Partial least squares-discriminant analysis (PLS-DA) for classification of high-dimensional (HD) data: a review of contemporary practice strategies and knowledge gaps. Analyst. 2018; 143(15):3526-39. https://doi.org/10.1039/c8an00599k.

39. Kieffer DA, Piccolo BD, Vaziri ND, Liu S, Lau WL, Khazaeli M, Nazertehrani S, Moore ME, Marco ML, Martin RJ, Adams SH. Resistant starch alters gut microbiome and metabolomic profiles concurrent with amelioration of chronic kidney disease in rats. Am J Physiol Renal Physiol. 2016;310(9):F85771. https://doi.org/10.1152/ajprenal.00513.2015.

40. Wishart DS, Jewison T, Guo AC, Wilson M, Knox C, Liu Y, Djoumbou Y, Mandal R, Aziat F, Dong E, Bouatra S, Sinelnikov I, Arndt D, Xia J, Liu P, Yallou F, Bjorndahl $T$, Perez-Pineiro $R$, Eisner $R$, Allen F, Neveu V, Greiner $R$, Scalbert A HMDB 3.0--The human metabolome database in 2013. Nucleic Acids Res 2013, 41(Database issue):D801-D807. doi: https://doi.org/10.1093/nar/gks1065.

41. Zhu ZJ, Schultz AW, Wang J, Johnson CH, Yannone SM, Patti GJ, Siuzdak G. Liquid chromatography quadrupole time-of-flight mass spectrometry characterization of metabolites guided by the METLIN database. Nat Protoc. 2013;8(3):451-60. https://doi.org/10.1038/nprot.2013.004.

42. Oksanen J, Blanchet FG, Kindt R, Legendre P, O'Hara RB, Simpson GL, Solymos P, Stevens MHH, Wagner H. Package "vegan": community ecology package. Time International. 2012;1997(6):15-7. https://doi.org/10.1002/ltl.4 0619970607. 
43. Xu J, Li Y, Yang Z, Li C, Liang H, Wu Z, Pu W. Yeast probiotics shape the gut microbiome and improve the health of early-weaned piglets. Front Microbiol. 2018;9:2011. https://doi.org/10.3389/fmicb.2018.02011.

44. Wang K, Cao G, Zhang H, Li Q, Yang C. Effects of Clostridium butyricum and Enterococcus faecalis on growth performance, immune function, intestinal morphology, volatile fatty acids, and intestinal flora in a piglet model. Food Funct. 2019;10(12):7844-54. https://doi.org/10.1039/c9fo01650c.

45. He Y, Kim K, Kovanda L, Jinno C, Song M, Chase J, Li X, Tan B, Liu Y. Bacillus subtilis: a potential growth promoter in weaned pigs in comparison to carbadox. J Anim Sci. 2020;98(9). https://doi.org/10.1093/jas/skaa290.

46. Li H, Zhou Y, Ling H, Luo L, Qi D, Feng L. The effect of dietary supplementation with Clostridium butyricum on the growth performance, immunity, intestinal microbiota and disease resistance of tilapia (Oreochromis niloticus). PLoS One. 2019;14(12):e0223428. https://doi.org/1 0.1371/journal.pone.0223428.

47. Qiao J, Li H, Li Y. Dietary Clostridium butyricum supplementation modifies significantly the liver transcriptomic profile in weaned piglets. J Anim Physiol Anim Nutr. 2020;104(5):1410-23. https://doi.org/10.1111/jpn.13326.

48. Sato Y, Kuroki Y, Oka K, Takahashi M, Rao S, Sukegawa S, Fujimura T. Effects of dietary supplementation with enterococcus faecium and Clostridium butyricum, either alone or in combination, on growth and fecal microbiota composition of post-weaning pigs at a commercial farm. Front Vet Sci. 2019;6:26. https://doi.org/10.3389/fvets.2019.00026.

49. Zhang ST, Shi Y, Zhang SL, Wang HK. Progress on the studies and application of Clostridium butyricum. Biotechnol Bull. 2013;9:27-33. https:// doi.org/10.13560/j.cnki.biotech.bull.1985.2013.09.004.

50. Cho I, Blaser MJ. The human microbiome: at the interface of health and disease. Nat Rev Genet. 2012;13(4):260-70. https://doi.org/10.1038/nrg3182.

51. Shen J, Zhang B, Wei G, Pang X, Wei H, Li M, Zhang Y, Jia W, Zhao L. Molecular profiling of the Clostridium leptum subgroup in human fecal microflora by PCR-denaturing gradient gel electrophoresis and clone library analysis. Appl Environ Microbiol. 2006;72(8):5232-8. https://doi.org/10.112 8/AEM.00151-06

52. Nilsson PM, Fåk F. The intestinal microbiota affects health and disease. Dietary intake and genetic factors control the composition of the bacterial flora. Lakartidningen. 2015;112:DFH6. https://lakartidningen.se/klinik-ochvetensk-1/kommentar/2015/04/tarmens-mikrobiota-inverkar-pa-halsa-ochsjukdom/.

53. Zhang D, Ji H, Liu H, Wang S, Wang J, Wang Y. Changes in the diversity and composition of gut microbiota of weaned piglets after oral administration of Lactobacillus or an antibiotic. Appl Microbiol Biotechnol. 2016;100(23): 10081-93. https://doi.org/10.1007/s00253-016-7845-5.

54. Zhang J, Chen X, Liu P, Zhao J, Sun J, Guan W, Johnston L, Levesque CL, Fan P, He T, Zhang G, Ma X. Dietary Clostridium butyricum induces a phased shift in fecal microbiota structure and increases the acetic acid-producing bacteria in a weaned piglet model. J Agric Food Chem. 2018;66(20):515766. https://doi.org/10.1021/acs.jafc.8b01253.

55. Zhu Y, Wang C, Li F. Impact of dietary fiber/starch ratio in shaping caecal microbiota in rabbits. Can J Microbiol. 2015;61(10):771-84. https://doi.org/ 0.1139/cjm-2015-0201.

56. Thomas F, Hehemann J-H, Rebuffet E, Czjzek M, Michel G. Environmental and gut bacteroidetes: the food connection. Front Microbiol. 2011;2:93. https://doi.org/10.3389/fmicb.2011.00093.

57. Magrone T, Jirillo $E$. The interplay between the gut immune system and microbiota in health and disease: nutraceutical intervention for restoring intestinal homeostasis. Curr Pharm Des. 2013;19(7):1329-42. https://doi.org/1 $0.2174 / 138161213804805793$

58. Pellegrini S, Sordi V, Bolla AM, Saita D, Ferrarese R, Canducci F, Clementi M, Invernizzi F, Mariani A, Bonfanti R, Barera G, Testoni PA, Doglioni C, Bosi E, Piemonti L. Duodenal mucosa of patients with type 1 diabetes shows distinctive inflammatory profile and microbiota. J Clin Endocrinol Metab. 2017;102(5):1468-77. https://doi.org/10.1210/jc.2016-3222.

59. Zhu W, Lin K, Li K, Deng X, Li C. Reshaped fecal gut microbiota composition by the intake of high molecular weight persimmon tannin in normal and high-cholesterol diet-fed rats. Food Funct. 2018;9(1):541-51. https://doi. org/10.1039/c7fo00995j.

60. Ley RE, Turnbaugh PJ, Klein S, Gordon Jl. Microbial ecology: human gut microbes associated with obesity. Nature. 2006;444(7122):1022-3. https:// doi.org/10.1038/4441022a.

61. Fontaine MA, Diane A, Singh VP, Mangat R, Proctor SD. Low birth weight causes insulin resistance and aberrant intestinal lipid metabolism independent of microbiota abundance in landrace-large White pigs. FASEB J. 2019;33(8):9250-62. https://doi.org/10.1096/fj.201801302RR.

62. Ushiroda C, Naito Y, Takagi T, Uchiyama K, Mizushima K, Higashimura Y, Yasukawa Z, Okubo T, Inoue R, Honda A. Green tea polyphenol (epigallocatechin-3-gallate) improves gut dysbiosis and serum bile acids dysregulation in high-fat diet-fed mice. J Clin Biochem Nutri. 2019;65(1):3446. https://doi.org/10.3164/jcbn.18-116.

63. Tajima K, Aminov Rl, Nagamine T, Ogata K, Nakamura M, Matsui H, Benno Y. Rumen bacterial diversity as determined by sequence analysis of $16 \mathrm{~S}$ rDNA libraries. FEMS Microbiol Ecol. 1999;29(2):159-69. https://doi.org/10.1111/j.1 574-6941.1999.tb00607.x.

64. Matsui H, Ogata K, Tajima K, Nakamura M, Nagamine T, Aminov RI, Benno Y. Phenotypic characterization of polysaccharidases produced by four Prevotella type strains. Curr Microbiol. 2000;41(1):45-9. https://doi.org/10.1 007/s002840010089.

65. Kim HB, Borewicz K, White BA, Singer RS, Sreevatsan S, Tu ZJ, Isaacson RE. Longitudinal investigation of the age-related bacterial diversity in the feces of commercial pigs. Vet Microbiol. 2011;153(1-2):124-33. https://doi.org/10.1 016/j.vetmic.2011.05.021

66. Yoshikawa S, Araoka R, Kajihara Y, Ito T, Miyamoto H, Kodama H. Valerate production by Megasphaera elsdenii isolated from pig feces. J Biosci Bioeng. 2018;125(5):519-24. https://doi.org/10.1016/j.jbiosc.2017.12.016.

67. Hashizume K, Tsukahara T, Yamada K, Koyama H, Ushida K. Megasphaera elsdenii JCM1772T normalizes hyperlactate production in the large intestine of fructooligosaccharide-fed rats by stimulating butyrate production. J Nutr. 2003;133(10):3187-90. https://doi.org/10.1046/j.1365-277X.2003.00466.X.

68. Xie M, Chen G, Wan P, Dai Z, Hu B, Chen L, Ou S, Zeng X, Sun Y. Modulating effects of dicaffeoylquinic acids from ilex kudingcha on intestinal microecology in vitro. J Agric Food Chem. 2017;65(47):10185-96. https://doi.org/10.1021/acs.jafc.7b03992.

69. Biddle A, Stewart L, Blanchard J, Leschine S. Untangling the genetic basis of fibrolytic specialization by Lachnospiraceae and Ruminococcaceae in diverse gut communities. Diversity. 2013;5(3):627-40. https://doi.org/10.3390/d5030627.

70. Louis P, Flint HJ. Diversity, metabolism and microbial ecology of butyrateproducing bacteria from the human large intestine. FEMS Microbiol Lett. 2009:294(1):1-8. https://doi.org/10.1111/j.1574-6968.2009.01514.x.

71. Huws SA, Kim EJ, Lee MRF, Scott MB, Tweed JKS, Pinloche E, Wallace RJ, Scollan ND. As yet uncultured bacteria phylogenetically classified as Prevotella, Lachnospiraceae incertae sedis and unclassified Bacteroidales, Clostridiales and Ruminococcaceae may play a predominant role in ruminal biohydrogenation. Environ Microbiol. 2011;13(6):1500-12. https://doi.org/1 0.1111/j.1462-2920.2011.02452.x.

72. Gao R, Zhu C, Li H, Yin M, Pan C, Huang L, Kong C, Wang X, Zhang Y, Qu S, Qin $H$. Dysbiosis signatures of gut microbiota along the sequence from healthy, young patients to those with overweight and obesity. Obesity (Silver Spring). 2018;26(2):351-61. https://doi.org/10.1002/oby.22088.

73. Gophna U, Konikoff T, Nielsen HB. Oscillospira and related bacteria - from metagenomic species to metabolic features. Environ Microbiol. 2017;19(3): 835-41. https://doi.org/10.1111/1462-2920.13658.

74. Smyatskaya J, Bazarnova J, Eliseeva S, Zhilinskaya N, Barsukova N, Aronova E, Korzh A. Metabiotics in molecular nutrition: history and practice. E3S Web of Conferences 2020, 161. doi: https://doi.org/10.1051/e3sconf/202016102005.

75. Konikoff T, Gophna U. Oscillospira: a central, enigmatic component of the human gut microbiota. Trends Microbiol. 2016;24(7):523-4. https://doi.org/1 0.1016/j.tim.2016.02.015.

76. Dong S, Xia YF. Research Progress of Metabonomics in arthritis. Strait Pharmaceutical J. 2016;28(3):1-5. https://doi.org/10.3969/j.issn.1006-3765.201 6.03.001.

77. Ma N, Karam I, Liu X-W, Kong X-J, Qin Z, Li S-H, Jiao Z-H, Dong P-C, Yang YJ, Li J-Y. UPLC-Q-TOF/MS-based urine and plasma metabonomics study on the ameliorative effects of aspirin eugenol ester in hyperlipidemia rats. Toxicol Appl Pharmacol. 2017;332:40-51. https://doi.org/10.1016/j.taap.2017. 07.013

78. Cartlidge CR, U MRA, AMA A, Taylor-Robinson SD. The utility of biomarkers in hepatocellular carcinoma: review of urine-based H-NMR studies - what the clinician needs to know. Int J Gen Med. 2017;10:431-42. https://doi. org/10.2147/IJGM.S150312.

79. Yip LY, Aw CC, Lee SH, Hong YS, Ku HC, Xu WH, Chan JMX, Cheong EJY, Chng KR, Ng AHQ, Nagarajan N, Mahendran R, Lee YK, Browne ER, Chan ECY. The liver-gut microbiota axis modulates hepatotoxicity of tacrine in the rat. Hepatology. 2018;67(1):282-95. https://doi.org/10.1002/hep.29327. 
80. Deng D, Jian C, Lei L, Zhou Y, McSweeney C, Dong F, Shen Y, Zou D, Wang $Y$, Wu Y, Zhang L, Mao Y. A prenatal interruption of DISC1 function in the brain exhibits a lasting impact on adult behaviors, brain metabolism, and interneuron development. Oncotarget. 2017;8(49):84798-817. https://doi. org/10.18632/oncotarget.21381

81. Nie C, Zhang W, Wang Y, Liu Y, Ge W, Liu J. Tissue lipid metabolism and hepatic metabolomic profiling in response to supplementation of fermented cottonseed meal in the diets of broiler chickens. J Zhejiang Univ Sci B. 2015;16(6):447-55. https://doi.org/10.1631/jzus.B1400255.

82. Nobeli I, Thornton JM. A bioinformatician's view of the metabolome. Bioessays. 2006;28(5):534-45. https://doi.org/10.1002/bies.20414.

83. Liu Y, Li Y, Feng X, Wang Z, Xia Z. Dietary supplementation with Clostridium butyricum modulates serum lipid metabolism, meat quality, and the amino acid and fatty acid composition of Peking ducks. Poult Sci. 2018;97(9):321829. https://doi.org/10.3382/ps/pey162.

84. Moinard C, Cynober L. Citrulline: a new player in the control of nitrogen homeostasis. J Nutr. 2007;137(6 Suppl 2):1621S-5S. https://doi.org/10.1093/ jn/137.6.1621S.

85. Yin J, Ma J, Li Y, Ma X, Chen J, Zhang H, Wu X, Li F, Liu Z, Li T, Yin Y. Branched-chain amino acids, especially of leucine and valine, mediate the protein restricted response in a piglet model. Food Funct. 2020;11(2):130411. https://doi.org/10.1039/c9fo01757g.

86. Campos-Ferraz PL, Bozza T, Nicastro H, Lancha AH Jr. Distinct effects of leucine or a mixture of the branched-chain amino acids (leucine, isoleucine, and valine) supplementation on resistance to fatigue, and muscle and liverglycogen degradation, in trained rats. Nutrition. 2013;29(11-12):1388-94. https://doi.org/10.1016/j.nut.2013.05.003.

87. Colin-Gonzalez AL, Paz-Loyola AL, de Lima ME, Galvan-Arzate S, Seminotti B, Ribeiro CA, Leipnitz G, Souza DO, Wajner M, Santamaria A. Experimental evidence that 3-methylglutaric acid disturbs mitochondrial function and induced oxidative stress in rat brain synaptosomes: new converging mechanisms. Neurochem Res. 2016;41(10):2619-26. https://doi.org/10.1007/ s11064-016-1973-2.

88. Wu G, Bazer FW, Burghardt RC, Johnson GA, Kim SW, Knabe DA, Li P, Li X, McKnight JR, Satterfield MC, et al. Proline and hydroxyproline metabolism: implications for animal and human nutrition. Amino Acids. 2011;40(4):105363. https://doi.org/10.1007/s00726-010-0715-z.

89. Venter L, Mienie LJ, Vosloo A, Loots DT. Jansen van Rensburg P, Lindeque JZ. Effect of proline-enriched abalone feed on selected metabolite levels of slow-growing adult Haliotis midae. Aquac Res. 2019;50(4):1057-67. https:// doi.org/10.1111/are.13978.

90. Nash JE, Rocha HJ, Buchan V, Calder GA, Milne E, Quirke JF, Lobley GE. The effect of acute and chronic administration of the beta-agonist, cimaterol, on protein synthesis in ovine skin and muscle. Br J Nutr. 1994;71(4):501-13. https://doi.org/10.1079/BJN19940158.

91. Du XD, Wu YL, Yang HJ, Yang T. Simultaneous determination of $10 \beta 2-$ agonists in swine urine using liquid chromatography-tandem mass spectrometry and multi-walled carbon nanotubes as a reversed dispersive solid phase extraction sorbent. J Chromatogr A. 2012;1260:25-32. https:// doi.org/10.1016/j.chroma.2012.08.066.

92. Tashiro M, Mochizuki H, Sakurada Y, Iwabuchi K, Kato M, Itoh M, Yanai K. IV. 3. Imaging of histamine $\mathrm{Hi}$ receptors in human brain and impaired cognitive performance induced by second generation antihistamines. CYRIC annual report 2001. p. 155-159.

93. Kang W, Choi D, Park T. Dietary suberic acid protects against uvb-induced skin photoaging in hairless mice. Nutrients. 2019;11(12). https://doi.org/10.33 90/nu11122948 Dietary Suberic Acid Protects Against UVB-Induced Skin Photoaging in Hairless Mice, 11, 12.

94. Fitton A, Goa KL. Azelaic acid. A review of its pharmacological properties and therapeutic efficacy in acne and hyperpigmentary skin disorders. Drugs. 1991;41(5):780-98. https://doi.org/10.2165/00003495-199141050-00007.

95. Roager HM, Licht TR. Microbial tryptophan catabolites in health and disease Nat Commun. 2018;9(1):3294. https://doi.org/10.1038/s41467-018-05470-4.

96. Keszthelyi D, Troost FJ, Masclee AAM. Understanding the role of tryptophan and serotonin metabolism in gastrointestinal function. Neurogastroenterol Motil. 2009;21(12):1239-49. https://doi.org/10.1111/j.1365-2982.2009.01370.x.

97. Bansal T, Alaniz RC, Wood TK, Jayaraman A. The bacterial signal indole increases epithelial-cell tight-junction resistance and attenuates indicators of inflammation. Proc Natl Acad Sci U S A. 2010;107(1):228-33. https://doi. org/10.1073/pnas.0906112107.
98. Oluwagbemigun K, Anesi A, Ulaszewska M, Clarke G, Alexy U, Schmid M, Roden M, Herder C, Mattivi F, Nöthlings U. Longitudinal relationship of amino acids and indole metabolites with long-term body mass index and cardiometabolic risk markers in young individuals. Sci Rep 2020, 10(1). doi: https://doi.org/10.1038/s41598-020-63313-Z,.

99. Favennec M, Hennart B, Caiazzo R, Leloire A, Yengo L, Verbanck M, Arredouani A, Marre M, Pigeyre M, Bessede A, Guillemin GJ, Chinetti G, Staels B, Pattou F, Balkau B, Allorge D, Froguel P, Poulain-Godefroy O. The kynurenine pathway is activated in human obesity and shifted toward kynurenine monooxygenase activation. Obesity (Silver Spring). 2015;23(10): 2066-74. https://doi.org/10.1002/oby.21199.

100. Anaya JM, Bollag WB, Hamrick MW, Isales CM. The role of tryptophan metabolites in musculoskeletal stem cell aging. Int J Mol Sci. 2020;21(18). https://doi.org/10.3390/ijms21186670 The Role of Tryptophan Metabolites in Musculoskeletal Stem Cell Aging, 21, 18

101. Vascellari S, Palmas V, Melis M, Pisanu S, Cusano R, Uva P, Perra D, Madau V, Sarchioto M, Oppo V, et al. Gut microbiota and metabolome alterations associated with parkinson's disease. mSystems. 2020;5(5). https://doi.org/1 0.1128/mSystems.00561-20.

\section{Publisher's Note}

Springer Nature remains neutral with regard to jurisdictional claims in published maps and institutional affiliations.
Ready to submit your research? Choose BMC and benefit from:

- fast, convenient online submission

- thorough peer review by experienced researchers in your field

- rapid publication on acceptance

- support for research data, including large and complex data types

- gold Open Access which fosters wider collaboration and increased citations

- maximum visibility for your research: over $100 \mathrm{M}$ website views per year

At BMC, research is always in progress.

Learn more biomedcentral.com/submissions 